\title{
¿Es necesario profundizar en la relación entre docente de matemáticas y la formación de las actitudes y creencias hacia la disciplina?
}

\author{
¿Is it necessary to analyze the relationship between mathematics teacher and the \\ shaping of attitudes and the beliefs toward this discipline?
}

\author{
Ronny Gamboa-Araya \\ rgamboa@una.cr \\ Universidad Nacional. \\ Heredia, Costa Rica.
}

Recibido-Received: 19/feb/2015 / Aceptado-Accepted: 5/may/2015 / Publicado-Published: 31/ene /2016.

\begin{abstract}
Resumen
La problemática asociada con la enseñanza y aprendizaje de las matemáticas ha sido una preocupación recurrente en varios países. El dominio afectivo del alumnado, dentro de este contexto, ha surgido como un elemento relevante que permite explicar algunos aspectos sobre ella. Desde esta perspectiva, surge la necesidad de profundizar en la influencia que el personal docente posee en el dominio afectivo de sus estudiantes, pues lo que hace en el aula podría ayudar a afianzar o modificar las actitudes y creencias del estudiantado. El objetivo de este artículo es señalar aspectos relacionados con el domino afectivo en matemáticas que poseen influencia en la enseñanza y aprendizaje de la disciplina y la necesidad de abordarlos desde la percepción del profesorado. El propósito es que, desde su labor diaria, modifique su quehacer e incentive un cambio de imagen de la materia. Para ello se presentan los resultados de distintas investigaciones que evidencian el papel del dominio afectivo, la influencia del personal docente y la necesidad realizar mayor investigación sobre el papel del profesorado.
\end{abstract}

Palabras claves: Docente, estudiantes, actitudes, creencias, matemáticas.

\begin{abstract}
Problems associated with teaching and learning mathematics have been a recurrent concern in several countries. The affective domain of students, in this context, has emerged as a relevant element that allows explaining some aspects of those problems. The need to explore in more detail the influence of teachers in the affective domain of students arises from this perspective, since what he/she does in the classroom could help strengthen or modify the attitudes and beliefs of students. This article aims to point out issues related to the affective domain in mathematics that have influenced teaching and learning the discipline, as well as the need to address them from the teaching staff perception. The purpose is to modify their work and encourage an image change of the discipline through their daily work. For this matter, conclusions of different investigations are presented showing the role of the affective domain, the influence of teaching staff and the need to carry out further research on the role of teachers.
\end{abstract}

Keywords: teachers, students, attitudes, beliefs, Mathematics.

$\mathrm{Al}$ analizar los datos sobre rendimiento académico, existe coincidencia con respecto a los bajos resultados en matemáticas en todos los niveles educativos. Normalmente se indica que 
estos resultados se deben a que las matemáticas son muy difíciles, por lo que es normal que el rendimiento académico en la disciplina sea bajo (Hidalgo, Maroto y Palacios, 2004). Aunque no se cuestiona su dificultad intrínseca, Hidalgo et al. (2004) citan que en el análisis del proceso de enseñanza y aprendizaje de la disciplina, no se pueden obviar sus características de abstracción, inducción, jerarquización, globalización, rigor, entre otras. Por esta razón, indican que para poder asimilar las matemáticas se requiere de un gran esfuerzo y de la utilización de estrategias cognitivas propias; pero, además, se debe tomar en cuenta que el aprendizaje matemático es acumulativo, por lo que los problemas de primaria se heredan en secundaria, así como que los de primaria y secundaria impactan la educación superior.

El rendimiento académico en matemáticas constituye uno de los desafíos permanentes en la mayoría de los sistemas educativos no sólo porque las matemáticas son consideradas como una de las asignaturas fundamentales en el currículum escolar, sino también, por la contribución al desarrollo del conocimiento cognitivo del niño y por la funcionalidad que poseen la mayoría de los aprendizajes matemáticos en la vida adulta. Dada esta importancia, en las sociedades modernas occidentales existe una creciente preocupación por el hecho de que una parte importante de los alumnos, y también la población en general, tiene relevantes dificultades para comprender y utilizar los conocimientos matemáticos. (Núñez et al., 2005, p. 2389)

La problemática que enfrentan la mayoría de estudiantes en matemáticas ha sido un tema recurrente en diferentes foros y congresos nacionales e internacionales. Chaves, Castillo y Gamboa (2008) indican que muchos investigadores apuntan que el origen de esta problemática, y el mismo rechazo hacia esta disciplina, no obedece únicamente a asuntos relacionados con su naturaleza, sino que son el resultado de una serie de estereotipos creados a su alrededor y que se transmiten en el entorno familiar y educativo. Este hecho provoca que el estudiantado adquiera ciertos prejuicios con respecto al aprendizaje matemático, los cuales afectan significativamente el proceso de su enseñanza y aprendizaje.

Por ello, Amirali (2010) indica que aunque las matemáticas son el núcleo de muchas carreras que contribuyen con el desarrollo de la sociedad, a la mayoría de la gente, en general, y estudiantes, en particular, no les gustan. La imagen de la disciplina como algo difícil, fuera del alcance para muchas personas, importante; pero abstracta y sin conexión con la vida, es muy común (Armenteros, 2009).

Al respecto, Gil, Blanco y Guerrero (2006) mencionan que un hecho que provoca en el estudiantado angustia y afecta su predisposición a la materia es, con frecuencia, los comentarios de la familia, amistades o compañeros y compañeras, e incluso del personal docente, quienes suelen manifestar sus amargas experiencias y sentimientos de fracaso en relación con las matemáticas; ello crea una atmósfera no muy apta para el aprendizaje de esta disciplina. Todo lo anterior influye directamente en cómo el estudiantado enfrenta esta asignatura, su desempeño y las actitudes y creencias en torno a esta. En el caso particular del personal docente de matemáticas, lo que hace en el aula, cómo aborda la materia, sus comentarios, trato, entre otros aspectos, pueden afectar directa o indirectamente lo que el estudiante cree y siente respecto a la disciplina.

El objetivo de este artículo es señalar aspectos relacionados con el domino afectivo en matemáticas que poseen influencia en la enseñanza y aprendizaje de la disciplina y la necesidad de abordarlos desde la percepción del profesorado. Lo anterior, sustentado en el hecho de que la práctica educativa 
ISSN Electrónico: 2215-3470

DOI: http://dx.doi.org/10.15359/ru.30-1.4
UNICIENCIA Vol. 30, No. 1, pp. 57-84. Enero-Junio, 2016.

URL: www.revistas.una.ac.cr/uniciencia Email: revistauniciencia@una.cr

docente, según diversos autores, posee influencia en la formación de las actitudes y creencias hacia las matemáticas por parte de sus estudiantes. El propósito es que, desde su labor diaria, el profesorado modifique su quehacer e incentive un cambio de imagen de la materia.

\section{Papel de las actitudes y creencias en matemáticas}

La enseñanza y aprendizaje de las matemáticas se asocia, comúnmente, con bajos resultados, fracasos académicos, obstáculos cognitivos y una serie de calificativos que han creado un ambiente negativo en torno a ella. Esta se ha caracterizado en ser una actividad que consiste en la explicación de conceptos, definiciones, teoremas y aplicaciones en donde se aprende haciendo ejercicios, bien sea de manera individual o en grupo, donde uno de los objetivos es impartir conocimientos y desarrollar habilidades de diferente naturaleza que permitan al estudiantado adquirir herramientas para aprender y desarrollar la capacidad para resolver problemas relacionados tanto con conceptos matemáticos, como procedimientos de tipo algorítmico (Pérez, 2008).

En este proceso, las actitudes y creencias estudiantiles y docentes han adquirido una importancia especial, lo cual se ve reflejado, según Candia (2009), en el aumento, en los últimos años, del número de publicaciones que relacionan la dimensión afectiva del individuo (actitudes, creencias y emociones) y la enseñanza y aprendizaje de las matemáticas.

Las actitudes y creencias respecto a las matemáticas constituyen constructos que influencian en el estudiantado su aprendizaje de la disciplina. Al respecto, Estrada y Bedoya (2010) apuntan que las actitudes estudiantiles hacia las matemáticas han sido objeto de medición en la última década, pues diversos reportes de investigación han sido publicados a nivel de secundaria y de universidad, lo que constituye una evidencia sólida acerca de la relación existente entre el rendimiento académico y la actitud.

Las actitudes afectan todo: las relaciones con los demás y la apertura de una persona a situaciones nuevas; si la actitud hacia una tarea es positiva es más probable que una persona disfrute haciéndola, pero si la actitud es negativa entonces la persona va a evitar hacer la tarea (Stramel, 2010). De esta forma, señala el autor, la actitud hacia las matemáticas puede afectar la disposición del individuo hacia la disciplina y hacia todo aquello que se refiere a las matemáticas.

Una actitud positiva por parte de los estudiantes permite desarrollar niveles de pensamiento donde el [sic] estudiantes sean artífices de su propio aprendizaje; que muestre los problemas y la teoría como relevantes y llenas de significado; en el que la matemática se utilice como una forma de comprender otras áreas del conocimiento; que permita, a través de la resolución de problemas, lograr altos niveles

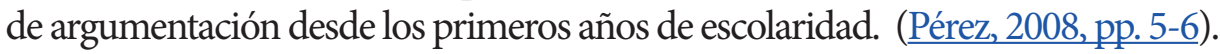

Por el contrario, una actitud negativa hacia las matemáticas significa tener una aversión hacia ellas, que a su vez puede reflejarse en evitar el uso de esta en la vida cotidiana (Belbase, 2010). De igual forma, el autor señala que una imagen negativa de las matemáticas desalienta para la elección de esta como asignatura principal en las escuelas y colegios y puede alejar al estudiantado de las carreras de ciencia y tecnología; además, que la ansiedad ocasionada por el disgusto hacia la disciplina, la preocupación y miedo que se crean debido a la mala imagen de estas provocan el surgimiento de una percepción negativa hacia ellas, que lleva a una actitud negativa en el largo plazo.

Incluso, Vieytes (2009) apunta que las actitudes negativas estudiantiles hacia las matemáticas pueden crear un gran obstáculo para lograr un aprendizaje efectivo. "Pobres actitudes hacia las 
matemáticas generalmente van acompañadas de un sentimiento de bajo auto-concepto que llega a veces al sentimiento de sentirse incompetente para resolver problemas matemáticos" (Vieytes, 2009, p. 30).

Para nadie es un secreto el deterioro progresivo y la desfavorable actitud hacia las matemáticas que han ido desarrollando las nuevas generaciones, en contraste con la creciente demanda por una población mejor preparada en esta área y de un mayor desarrollo científico y tecnológico (Pérez, 2008). Por esta razón, debido a la importancia de que los grupos de estudiantes tengan una imagen positiva de las matemáticas, ha surgido la necesidad de explorar sus concepciones existentes y la actitud hacia dicha disciplina; pues, con conciencia de sus concepciones, se podrá responder a estas a través del diseño de una enseñanza y aprendizaje de las matemáticas que permitan afianzarlas o cambiarlas (․ㅕirali, 2010).

Pero, además de explorar sus actitudes hacia esta área, se hace necesario profundizar en el origen de estas. Al respecto, Yara (2009) apunta que la actitud de estudiantes hacia la disciplina puede ser influenciada por la actitud de su docente y su método de enseñanza, pues los estudios realizados han demostrado que los métodos de enseñanza de cada docente y su personalidad pueden influir en una actitud positiva hacia las matemáticas. En este sentido, Goodykoontz (2009) señala, como factores que afectan las actitudes estudiantiles, las características del maestro o maestra, de la enseñanza, de la clase, las evaluaciones y logros y las características y percepciones individuales. El autor anota, además, que hay muchas relaciones entre estos aspectos.

En cuanto a lo señalado anteriormente, Goodykoontz (2009) apunta que los primeros cuatro factores son externos al estudiantado, mientras que el último es interno y se basa en las percepciones de cada quien. Sin embargo, apunta que los factores externos desempeñan un importante papel al influir en las percepciones internas de cada estudiante y sus creencias.

Relationship Between Factors That Affect College

Students' Attitude Toward Mathematics

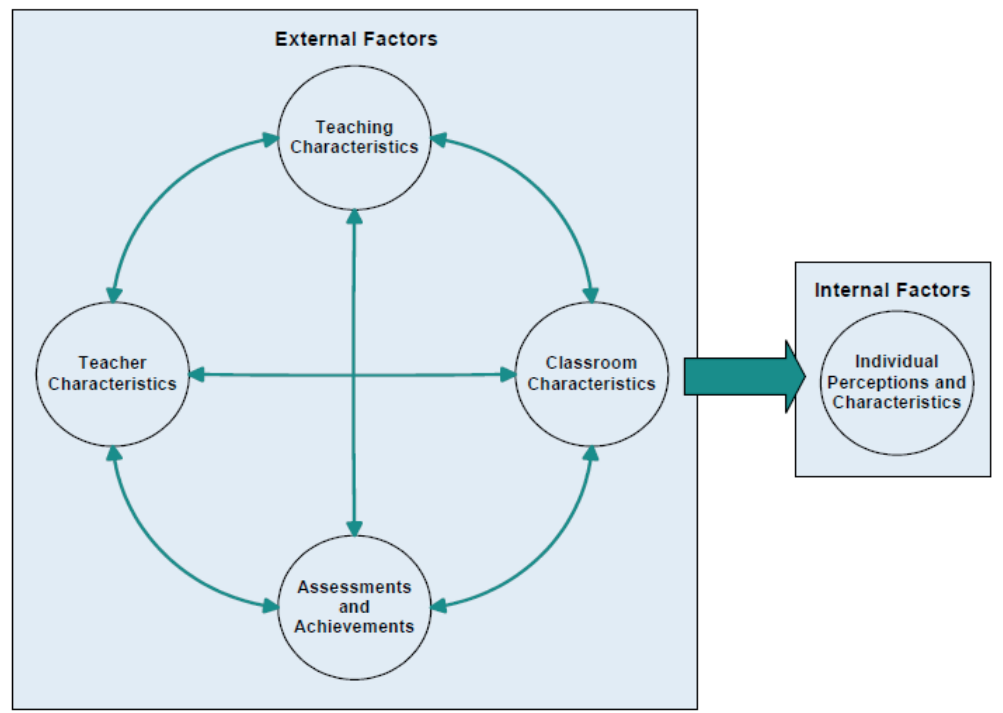

Imagen 1. Relaciones entre los factores que afectan las actitudes de estudiantes hacia las matemáticas, Goodykoontz (2009). Extraído de: Goodykoontz, E. (2009). Factors that Affect College Students' Attitudes toward Mathematics. Proceedings for the Twelfth Special Interest Group of the Mathematical Association of America on Research in Undergraduate Mathematics Education. North Carolina, USA. Recuperado de http://sigmaa.maa.org/rume/crume2009/Goodykoontz LONG.pdf 
ISSN Electrónico: 2215-3470

DOI: http://dx.doi.org/10.15359/ru.30-1.4
UNICIENCIA Vol. 30, No. 1, pp. 57-84. Enero-Junio, 2016.

URL: www.revistas.una.ac.cr/uniciencia Email: revistauniciencia@una.cr

En este sentido, Mato y de la Torre (2010) mencionan que es un hecho la influencia que el profesorado ejerce sobre la formación de actitudes, tanto positivas o negativas, hacia las matemáticas y en la motivación hacia su estudio, la ansiedad, el agrado, la utilidad y la confianza.

Relacionado con las actitudes hacia las matemáticas se encuentran las creencias hacia la disciplina. Respecto a ellas se señala que:

La importancia y la insistencia dada al tema de las creencias es, hoy en día, asumida y aceptada por el profesorado cada vez más dispuesto a reconocerlas como elementos de indiscutible valor e interés en el seguimiento y evaluación del proceso de enseñanzaaprendizaje. Sin embargo, se observa que faltan instrumentos adecuados para evaluar los sistemas de creencias acerca de matemáticas, no como una suma o yuxtaposición de creencias, sino como una red organizada en la que se tienen en cuenta los contextos socioculturales donde tiene lugar el aprendizaje. (Gómez-Chacón, 2007, p. 126)

En los últimos 25 años, la preocupación de distintas investigaciones sobre la competencia matemática de estudiantes ha hecho converger en cinco categorías de aptitudes lo que deberían adquirir para tener una buena disposición en matemáticas: conocimiento matemático, métodos heurísticos, metaconocimientos, habilidades de autorregulación y creencias positivas sobre las matemáticas y su aprendizaje (Gómez-Chacón, 2007).

Este último aspecto ha adquirido trascendencia debido a la relación que las creencias sobre las matemáticas poseen con el aprendizaje de la disciplina. En este sentido, Eleftherios y Theodosios (2007) apuntan que la dificultad de la materia se correlaciona con la creencia de la poca utilidad, con la aversión hacia ella, el bajo rendimiento y la poca capacidad matemática. Por otra parte, "el amor por las matemáticas" se correlaciona positivamente con el alto rendimiento y capacidad matemática.

Aunado a lo anterior, Sánchez (2008) indica que la concepción que el individuo posee sobre las matemáticas afecta la forma de trabajar los problemas matemáticos y señala que gran cantidad de estudiantes creen que solo los genios son capaces de entender esta disciplina; que las matemáticas que se enseñan en las escuelas no tiene relación con el mundo real, y que esta materia representa una ciencia acabada y encerrada en sí misma.

Como consecuencia de su experiencia previa, el estudiantado genera creencias que condicionarán no solo su aprendizaje sino, también, la forma en que utilizarán las matemáticas en el futuro (Estrada, 2002). Por ello, señala que constituyen una base para generar conocimiento, por lo que deben ser concebidas como un referente cognitivo que debe servir de soporte lógico y psicológico para condicionar, de alguna manera, los aspectos afectivos del estudiantado que le predispone para actuar según estas creencias.

En este sentido, Briley, Thompson e Iran-Nejad (2009) apuntan que quienes educan en matemáticas deben reconocer la interconexión de las creencias matemáticas de sus estudiantes y concientizarles sobre "el daño potencial" de la ingenua creencia matemática, ya que algunas de ellas pueden afectar negativamente su aprendizaje para la comprensión.

Por ello, la formación del estudiantado en el ámbito emocional y afectivo se fundamenta en la importancia que tienen los pensamientos y creencias en la explicación del comportamiento ante las actividades matemáticas, pues explican, en parte, los rechazos y las atracciones hacia estas, el profesorado que la enseña, la situación de aprendizaje en la que se desarrolla, la escuela, las demás personas o ellos mismos y ellas mismas (Candia, 2009). 
UNICIENCIA Vol. 30, No. 1, pp. 57-84. Enero-Junio, 2016.

ISSN Electrónico: 2215-3470

URL: www.revistas.una.ac.cr/uniciencia

Email: revistauniciencia@una.cr

Por medio de su sistema de creencias, una persona da significado y coherencia a su propio modelo de mundo. Cuestionar una de esas creencias puede provocar un desequilibrio en el sistema completo. Esta situación induce a que una persona se resista profundamente a modificar alguna de ellas. Por ello, en la planificación de la actividad académica, el educador o educadora debe tener conciencia de la importancia que juega el sistema de creencias del estudiantado.

Para explicar las creencias estudiantiles, según Gómez-Chacón, Op’t Eynde y De Corte (2006), no solo se deben tener en cuenta sus reacciones emocionales individualmente (aspectos microafectivos) y las variables (aspectos macroafectivas) a las que aquellas reacciones emocionales atenderían (sistemas de creencias de su entorno social, de la sociedad en general sobre matemáticas, entre otras), sino que se deben atender otros procesos sociales intermedios referentes a la difusión y obtención de información matemática, la mediación en el aprendizaje, la creación de opiniones y valoraciones grupales en la clase, la emergencia de redes de apoyo dentro del sistema de enseñanza o sistema de aprendizaje que favorece estas creencias.

Estos autores indican que la identificación de las diferentes categorías que constituyen el sistema de creencias de estudiantes hacia las matemáticas es un primer paso necesario para desentrañar el papel de las creencias en el aprendizaje matemático. Además, apuntan que si buscamos comprender la naturaleza y el funcionamiento de las creencias de estudiantes, plenamente, debemos identificar no solo las diferentes categorías de creencias y sus relaciones internas, sino también investigar cómo se relacionan con otras características del estudiantado, cómo es el contexto de clase y la influencia que otros actores poseen en la formación de estas. Por ejemplo, el personal docente.

Por lo tanto, es ampliamente aceptado que las actitudes y creencias del individuo influyen en el comportamiento de este en las matemáticas y en su desempeño en la disciplina (Akay y Boz, 2010; Briley et al., 2009; Eleftherios y Theodosios, 2007; Hekimoglu y Kittrell, 2010; Stramel, 2010; Suthar y Tarmizi, 2010; Vieytes, 2009).

El importante papel de las creencias, el afecto y la motivación en el aprendizaje de las matemáticas es bien reconocido en la educación matemática, pues las creencias de estudiantes sobre la disciplina y las actitudes que poseen tienen un impacto en su "compromiso" y rendimiento, especialmente en la resolución de problemas (Hassi y Laursen, 2009).

Conscientes de la importancia del factor emocional en la educación matemática, Eleftherios y Theodosios (2007) indican que uno de los propósitos de la enseñanza debe ser el cambio apropiado las actitudes y creencias estudiantiles, con el fin de mejorar su habilidad matemática. Pero para lograr ese cambio es necesario determinar no solo cuáles son las actitudes y creencias que poseen, sino además los factores asociados al origen de estos. Al respecto, Gómez-Chacón (2007) menciona que las creencias de estudiantes sobre la educación de las matemáticas están determinadas por el contexto social en el que participan, por sus necesidades psicológicas individuales, los deseos, las metas, entre otras. "En otras palabras, los sistemas de creencias están constituidos por creencias sobre la Educación Matemática, creencias sobre sí mismos, y creencias sobre el contexto" (GómezChacón, 2007, p. 127). En este contexto se incluye al personal docente.

Por otra parte, se señala que un aspecto crucial para que las matemáticas dejen de ser un elemento de exclusión es lograr la ruptura de los mitos relacionados con ellas (Armenteros, 2009). La mejor manera de explicar cómo los estados emocionales influyen en el rendimiento es partir de los pensamientos, las actitudes y las creencias que determinan los sentimientos y las emociones. "Es decir, no son los hechos reales, sino el significado y las evaluaciones que el 
ISSN Electrónico: 2215-3470 DOI: http://dx.doi.org/10.15359/ru.30-1.4
UNICIENCIA Vol. 30, No. 1, pp. 57-84. Enero-Junio, 2016. URL: www.revistas.una.ac.cr/uniciencia Email: revistauniciencia@una.cr

sujeto realiza las que producen cambios en las emociones y en los estados de ánimo" (Candia, 2009, p. 2). Pero lo anterior solamente se logrará, si se poseen elementos que permitan describir la forma que dichas conductas se pueden cambiar.

Como ya se mencionó anteriormente, la dimensión afectiva del individuo incluye actitudes, creencias y emociones. Junor, Thomas y Vidakovic (2009) indican que las actitudes y creencias de un individuo están íntimamente relacionadas. Los autores citan a Arp (1999), quien expresa que la distinción entre los dos es difícil debido a que las actitudes tienen componentes cognitivos y afectivos en contraposición a las creencias que solo tienen un componente cognitivo.

Al respecto, Bazán y Aparicio (2006) indican que ante una situación de aprendizaje, un estudiante puede reaccionar positiva o negativamente, de acuerdo con sus creencias acerca de sí mismo y con la asignatura que cursa. Si se reproduce la misma reacción afectiva muchas veces (frustración, satisfacción, entre otras), esta puede convertirse en una actitud; y las actitudes, a su vez, influyen en las creencias y contribuyen a la formación del alumnado. Desde esta perspectiva, los autores indican que la actitud es una disposición personal, idiosincrásica, presente en todos los individuos, dirigida a objetos, eventos o personas, que se organiza en el plano de las representaciones, y que considera los dominios cognitivo, afectivo y conativo.

Es evidente que la interrelación existente entre la educación matemática y los componentes del dominio afectivo influencian fuertemente la enseñanza y aprendizaje de las matemáticas; por ello, autores como Chaves et al. (2008) señalan la importancia de tomar en cuenta los diferentes factores que configuran el dominio afectivo en los procesos educativos, en particular, las creencias y actitudes, y sus interrelaciones.

En general, una gran cantidad de estudiantes poseen ciertas creencias y actitudes hacia las matemáticas y a la forma en que tradicionalmente se enseña y evalúa, lo cual dificulta su aprendizaje. Particularmente, el sistema de creencias, respecto a la enseñanza y aprendizaje de las matemáticas constituye un conjunto estructurado de grupos de visiones, concepciones, valores o pensamientos que tiene cada estudiante sobre ella. Esto permite explicar el rechazo o el gusto por la disciplina, el profesorado, las estrategias de enseñanza, la institución educativa e incluso, hacia sí.

El mismo proceso educativo puede establecer cambios en los componentes afectivos de sus estudiantes, por medio de reacciones emocionales que se suscitan durante dicho proceso. Por esta razón, resulta de vital importancia que la mediación pedagógica genere un ambiente de aprendizaje agradable, capaz de propiciar emociones y actitudes positivas, lo cual transforme aquellas creencias originales que pudieran afectar la adquisición de conceptos matemáticos (Chaves et al., 2008). Por ello, se requiere de un trabajo arduo y continuo, el cual permita desestabilizar el sistema de creencias en la medida que genere comportamientos diferentes por parte del estudiantado. Si las actividades persisten a través de un periodo prolongado, esto provocaría una transformación de las creencias.

Al respecto, Hekimoglu y Kittrell (2010) señalan que un programa de matemáticas exitoso debe centrarse en encontrar maneras de atender las necesidades de sus estudiantes, esperanzas y temores, donde se consideren sus creencias sobre las matemáticas, se incentive la construcción de los conocimientos y la confianza en sus habilidades matemáticas. Este programa debe aumentar la motivación personal y el entusiasmo por estudiar dicha disciplina.

Comprender realmente lo que el estudiantado cree implica situarse dentro del contexto personal relevante para este y dentro del contexto sociohistórico, es decir, analizar las relaciones 
con el resto de estudiantes y con otras características del entorno. Esto aportará no solamente una mejor comprensión de sus creencias y, por ende de sus actitudes, sino que permitirá clarificar algunos de sus orígenes y los mecanismos que las desencadenan (Gómez-Chacón et al., 2006). Así, los referentes afectivos tales como las emociones, las creencias o las actitudes están comprometidos e involucrados con el éxito o con el fracaso estudiantil (Martínez, 2008).

\section{El dominio afectivo en matemáticas: Un campo de investigación}

Las distintas experiencias que cada estudiante ha tenido respecto a las matemáticas y su proceso de aprendizaje determinan, en parte, la forma en cómo se desenvuelve en la disciplina. La tradicional imagen negativa que ha rodeado a esta materia ha provocado una serie de actitudes y creencias en el estudiantado que han inducido, en algunos casos, a un bloqueo cognitivo. En este sentido, Armenteros (2009) indica que la imagen social negativa de las matemáticas se ve reflejada en el comportamiento de gran cantidad de estudiantes en las aulas, no solo porque manifiestan una actitud de rechazo hacia ellas y a parte de sus docentes, sino porque también hacen alarde de obtener malos resultados en dicha disciplina como una forma de sobresalir en el grupo de amistades.

Al respecto

Se dice que la sociedad excluye con las matemáticas, porque sin saber matemáticas, no podemos formar parte de ese breve porcentaje de personas privilegiadas que dominan al menos los aspectos básicos y prácticos de las matemáticas. En una sociedad orientada a la ocupación, donde las credenciales son un criterio necesario para entrar en el mercado laboral, que el fracaso en las matemáticas trunque a alguien su carrera, es una forma clara de exclusión. (Armenteros, 2009, p. 20)

Así, se evidencia que la misma sociedad se ha encargado de promover y divulgar ciertos sentimientos sobre las matemáticas, los cuales contribuyen a que la juventud adquiera creencias con respecto a que "las matemáticas son difíciles, complicadas y destinadas a los «más inteligentes»" (Gil et al., 2006, p. 552).

Sin embargo, Núñez et al. (2005) apuntan que el fracaso en el área de las matemáticas no se concentra únicamente en los alumnos o alumnas menos "capacitados", sino que cantidad de estudiantes con altos rendimientos en otras materias escolares, presentan bajos resultados en ellas. Por ello, señalan los autores, es general la percepción escolar de las matemáticas como un conocimiento complejo que genera sentimientos de ansiedad e intranquilidad, lo cual constituye una de las causas más frecuentes de frustraciones y actitudes negativas hacia la escuela.

La experiencia que tiene un estudiante al aprender matemáticas le provoca distintas reacciones emocionales que influyen en sus creencias, mientras que sus creencias influyen en su comportamiento en situaciones de aprendizaje y en su capacidad para aprender, haciendo con que la relación creencias aprendizaje sea cíclica. (De Faria, 2008, p. 10)

Por su parte, Belbase (2010) señala que desde una perspectiva psicológica, hay un mito general de que las matemáticas son un tema misterioso. Mientras que algunas personas afirman que les gusta otros aseveran que no; algunas sienten miedo ante esta disciplina mientras que otras disfrutan de la resolución de problemas. Por ello, Vieytes (2009) indica que, en general, se puede deducir que si un estudiante ha tenido algún tipo de experiencia negativa con matemáticas esta 
ISSN Electrónico: 2215-3470 DOI: http://dx.doi.org/10.15359/ru.30-1.4
UNICIENCIA Vol. 30, No. 1, pp. 57-84. Enero-Junio, 2016. URL: www.revistas.una.ac.cr/uniciencia Email: revistauniciencia@una.cr

puede convertirse en una razón por la cual siente antipatía o miedo hacia la disciplina. Por esta razón, el estudio sobre las actitudes y creencias de estudiantes, comprendidas como parte del factor emocional en matemáticas, constituye un tema de especial importancia en educación matemática.

Respecto al factor emocional, Cubillo et al. (2010) señalan que este se constituye en un aspecto primordial en el aprendizaje y que se ha venido tomando en consideración en los últimos años como un elemento que puede explicar, parcialmente, al menos, las dificultades que presenta las matemáticas para muchas personas. En este sentido, Chandía, Quiroga y Ulloa (2006) plantean cómo los estudios indican que cuando el estudiantado se enfrenta a situaciones adversas constantemente, la aparición de condiciones afectivas negativas dificulta el aprendizaje, pues establece ciertas creencias (cuyo sustento es absolutamente emocional) y las internaliza como verdades absolutas.

Relacionado con lo anterior, Núñez et al. (2005) indican que en los últimos años se ha constatado un aumento en el número de investigaciones que relacionan la dimensión afectiva del individuo (creencias, actitudes y emociones) y la enseñanza y aprendizaje de las matemáticas. Por ello, apuntan los autores, se puede mantener la hipótesis de que las actitudes, creencias y emociones influyen tanto en el éxito como en el bajo rendimiento y fracaso en el aprendizaje de las Matemáticas. En concordancia con lo señalado anteriormente, Estrada y Bedoya (2010) apuntan acerca de las numerosas investigaciones que se han realizado para conocer cuál es la actitud hacia las matemáticas tanto en estudiantes como en docentes en todos los niveles educativos.

Por su parte, Akay y Boz (2010) acotan que, debido a la existencia de una relación positiva entre la actitud hacia las matemáticas y el éxito en ellas, la actitud hacia estas se acepta como un factor determinante de éxito o fracaso, por lo que resulta muy importante mejorar las actitudes estudiantiles hacia las matemáticas y las creencias al respecto. En cuanto a ello, Hekimoglu y Kittrell (2010) mencionan la existencia de evidencia considerable para argumentar que las creencias de estudiantes, las actitudes y las experiencias previas son factores importantes e influyentes en su rendimiento matemático.

Debido a esto, Suthar y Tarmizi (2010) indican que la evidencia empírica ha demostrado cómo las creencias de estudiantes sobre las matemáticas son fundamentales en sus aspiraciones para la escogencia de una carrera universitaria, además de que están estrechamente correlacionadas con el rendimiento en la asignatura. Ante esta realidad, Vieytes (2009) apunta que la enseñanza de la disciplina está relacionada con las creencias, sentimientos y percepciones que el estudiantado tiene hacia ella.

Desde esta perspectiva, señala Vieytes (2009), las actitudes estudiantiles hacia las matemáticas juegan un importante papel en su aprovechamiento y participación. Chaves et al. (2008) indican que estos elementos (actitudes y creencias) incrementan la probabilidad de fracaso escolar, debido a la predisposición con la cual el estudiantado ingresa a los cursos de esta disciplina.

El aumento de los fracasos y de las bajas calificaciones en matemáticas, así como el disgusto por ellas, ha traído como consecuencia un mayor interés de los educadores y educadoras por encontrar una solución al problema. Por ello, la detección de estas actitudes y creencias podría considerarse como el primer paso para contrarrestar su influencia negativa en la efectividad del proceso de enseñanza y aprendizaje de las matemáticas.

El dominio afectivo en matemáticas incluye no solamente las actitudes y creencias hacia la disciplina; sin embargo, dado que este documento hace referencia a estos dos componentes, a continuación se presentan los resultados de estudios que profundizaron en ambos, tanto de forma separada como en conjunto. 
Con el propósito de mostrar un panorama sobre la teorización de las creencias y las actitudes de estudiantes, Hernández (2011) analizó una serie de documentos que abordaban las actitudes y creencias como tópico central, los cuales hacen referencia a investigaciones realizadas en distintos países en la década 2000 a 2010. El autor realizó una exploración de las investigaciones que abordaban el tema de las actitudes y creencias por separado, o bien en forma conjunta, pero enmarcadas todas en el contexto educativo. La mayoría de los trabajos eran de carácter empírico, por medio de investigación de campo y un gran porcentaje de ellos tenía a los alumnos y alumnas como sujetos de investigación.

Como parte de su trabajo, Hernández (2011) analizó 50 documentos, de los cuales 30\% comprendían el estudio de las actitudes y creencias en forma conjunta o hacían referencia a la afectividad en el campo educativo; el 34\% están dirigidos a la investigación de las creencias en educación y el 36\% abordaban las actitudes como línea directa de investigación en el proceso enseñanza y aprendizaje. Del total de documentos analizados, 35 correspondían a artículos publicados en revistas de investigación, once ponencias, un ensayo y tres capítulos de libros, de los cuales 33 comprendían el trabajo de campo como fuente básica de información.

En los reportes de investigación analizados por Hernández (2011), los sujetos de investigación corresponden a estudiantes en 41 casos, mientras que los nueve restantes se centraban en docentes. Las investigaciones sobre las creencias, actitudes y comportamientos del profesorado fueron consideradas para ampliar la comprensión teórica de los factores que influyen en las del alumnado.

Sobre el aspecto metodológico, Hernández (2011) apunta que en los documentos sobre los cuales se realizó el estudio, en general, no se especifica el método empleado. Solamente 19 de ellos (38\%) indican la metodología utilizada, de los cuales seis fueron cualitativas, seis descriptivas, cuatro cuantitativas, dos correlacionales y uno mixta. Respecto al método empleado, el autor apunta que seis emplearon el análisis bibliográfico, cinco el análisis descriptivo, tres el análisis estadístico, dos el método interpretativo, dos el etnográfico, uno el antropológico y uno el heurístico.

Los documentos analizados por Hernández (2011) eran de distintos países (España, México, Estados Unidos, Argentina, Colombia, Venezuela, Costa Rica, Malasia, Austria, Bélgica, Canadá, Inglaterra, Italia, Perú, Portugal), donde destaca España como el país origen de esta línea de investigación. Del trabajo de revisión realizado por Hernández (2011) se menciona:

La investigación en matemática educativa pone de manifiesto que las creencias de los estudiantes conforman aspectos decisivos en la estructuración de su realidad social y cultural. La valoración, el aprecio y desinterés por las matemáticas y su aprendizaje, tienen un componente afectivo que converge en la actitud hacia las matemáticas como asignatura de aprendizaje, hacia los métodos de enseñanza, hacia el docente y hacia el contexto estudiantil en su conjunto. La valoración que tiene el estudiante sobre la utilidad de las matemáticas lo predispone para dar respuestas organizadas mas allá de los sistemas psicológicos, incluyendo lo fisiológico, cognitivo y motivacional: estas son sus emociones. Tales emociones surgen en respuesta a un suceso, interno o externo, que tiene una carga de significado positiva o negativa en el individuo. (Hernández, 2011, párr. 112).

Con el propósito de brindar una visión general sobre el trabajo realizado en este campo, se presentan algunos resultados de trabajos de investigación realizados tanto a nivel internacional 
ISSN Electrónico: 2215-3470 DOI: http://dx.doi.org/10.15359/ru.30-1.4
UNICIENCIA Vol. 30, No. 1, pp. 57-84. Enero-Junio, 2016. URL: www.revistas.una.ac.cr/uniciencia Email: revistauniciencia@una.cr

como nacional, con base en una revisión bibliográfica que comprendió artículos de revistas, libros y tesis, tanto en formato electrónico como en "físico". Los estudios consultados se dividieron en tres grupos: los que abordaban las actitudes hacia las matemáticas, los que investigaron sobre las creencias hacia las matemáticas y aquellos que las indagaron en forma conjunta ambos temas.

\section{Actitudes hacia las matemáticas}

A nivel internacional existe amplia bibliografía en torno a esta temática. En Estados Unidos, por ejemplo, Tessema (2010) realizó un estudio cuantitativo para examinar la enseñanza en clase y las actitudes estudiantiles hacia las matemáticas en el nivel secundario. Para ello recolectaron datos a través de una encuesta tipo Likert que fue aplicada a 795 estudiantes de una secundaria.

El objetivo fue determinar la correlación entre la instrucción en el aula y las actitudes de los estudiantes hacia esta disciplina. Los resultados obtenidos mostraron que las correlaciones entre la instrucción en el aula y las actitudes de estudiantes fueron positivas para todos los grados. Los hallazgos apoyaron la opinión de que la instrucción en el aula tiene una relación directa con la actitud de estudiantes hacia las matemáticas.

En ese mismo año, pero en Colombia, Estrada y Bedoya (2010), como parte del diagnóstico de la educación matemática desarrollado en el municipio de Cartago, en el departamento del Valle del Cauca, acogieron la parte actitudinal de los estudiantes frente a las matemáticas, considerándolo como un posible factor predictor de la adquisición de conocimientos. Para esto elaboraron un instrumento (escala de actitudes) con el objetivo de medir la actitud hacia las matemáticas.

En el estudio participaron estudiantes de básica primaria y media con el objetivo principal de diagnosticar la actitud hacia las matemáticas en estudiantes de colegios del sector oficial y se llevó a cabo a través de un diseño cuantitativo-descriptivo. Se tomó como población de estudio a estudiantes de todas las instituciones públicas y privadas de la zona urbana del municipio de Cartago, que ofrecían educación básica o media durante el año 2009, y sobre la cual se realizó un muestreo aleatorio doblemente estratificado (por nivel escolar: $5^{\circ}, 9^{\circ}$ y $11^{\circ}$ y tipo de institución: pública y privada). El tamaño de la muestra fue de 665 estudiantes.

Entre las conclusiones obtenidas por los investigadores se pueden citar que la actitud hacia las matemáticas por parte de estudiantes de primaria y secundaria en la ciudad de Cartago está entre indiferente y positiva; que la actitud es positiva en grados inferiores y conforme se avanza académicamente esta actitud se desmejora, esto debido posiblemente a factores endógenos como formación del profesorado y ambiente de aprendizaje; que la actitud hacia las matemáticas es un componente importante en el proceso de enseñanza y aprendizaje.

Por su parte, Mato y de la Torre (2010), en Perú, realizaron un estudio con estudiantes de secundaria con el objetivo de contribuir a esclarecer la influencia que existe entre sus actitudes hacia las matemáticas y su rendimiento académico. Los participantes en este estudio fueron 1220 estudiantes (586 hombres y 634 mujeres) de $1^{\circ}, 2^{\circ}, 3^{\circ}$ y $4^{\circ}$ grado de educación secundaria obligatoria, quienes pertenecían a siete centros escolares públicos, privados o concertados. Para la recolección de los datos utilizaron un cuestionario con 19 ítems distribuidos en dos factores: la actitud del profesorado percibida por el alumnado y agrado y utilidad de las matemáticas en el futuro.

Las investigaciones indican que los resultados de su estudio permiten establecer algunas diferencias en función del tipo de centro escolar, pues los análisis efectuados indicaron que la actitud hacia las matemáticas varía en función del tipo de centro. En este sentido, reportan, respecto a la actitud del profesorado percibida por el alumnado y a la utilidad de las matemáticas, 
la existencia de valores que van creciendo según el siguiente orden: público periferia, público centro, concertado y privado. Respecto a la relación entre el rendimiento del alumnado y la variable actitud, reportan diferencias estadísticamente significativas en todas las categorías. Hacen mención a la no existencia de diferencias de rendimiento respecto al factor actitud del profesorado percibida por el alumnado cuando la calificación de este es bien, notable o sobresaliente. Sin embargo, señalan que sí existen diferencias en las calificaciones inferiores.

En España, Núñez et al. (2005) señalan datos relativos a la evolución de las diferentes dimensiones de las actitudes hacia las matemáticas con base en una amplia muestra de estudiantes de dos contextos educativos diferentes (brasileño y español) con edades entre los 9 y 16 años. Para ello, trabajaron con una muestra intencional de alumnado de educación primaria y educación secundaria obligatoria que consideró variables como el curso o nivel, el género, el tipo de colegio (público o privado), la zona geográfica (rural o urbana) y el contexto educativo (Sistema Educativo Español, SEE, y Sistema Educativo Brasileño, SEB). La muestra total fue de 5926 (2698 estudiantes del SEE y 3228 del SEB). A cada participante se le administró un cuestionario denominado Inventario de actitudes hacia las matemáticas, constituido por 86 ítems.

Los investigadores mencionan, respecto a los resultados, que no existen grandes diferencias en relación con las variables género, curso o zona geográfica. Afirman, en general, que se puede observar cómo, con el paso de los cursos, se produce un descenso de las expectativas de éxito futuro, la utilidad de las matemáticas, del interés por implicarse en el aprendizaje de la disciplina, de la competencia percibida para enfrentarse con éxito a las tareas asignadas, de la motivación de logro, de las expectativas de los padres respecto al logro futuro de los hijos en el área de las matemáticas, del interés por evitar mostrarse competente en la materia, de la atribución del fracaso a variables tales como ser el favorito del profesor o que el profesor no sabe enseñar, de que para rendir bien en matemáticas es necesario ser inteligente y de las expectativas de los profesores respecto al logro de los alumnos.

Al revisar los resultados, Núñez et al. (2005) mencionan, como aspecto relevante, que en ambas muestras el interés por las matemáticas decrece significativamente a medida que se asciende en los cursos escolares, tomando en cuenta la relevancia del conocimiento matemático en los estudios superiores. Relacionado con lo anterior, la utilidad de las matemáticas de cara al futuro presenta un descenso significativo más acentuado a medida que se avanza en los cursos académicos. Los investigadores indican que este hecho, tal vez, se revele por la forma en que se explican y enseñan las matemáticas, pues en muchos casos se presentan alejadas de la vida real y descontextualizada, por lo que al estudiantado se le dificulta percibirlas como útiles para resolver problemas de la vida cotidiana.

Los investigadores observaron, además, que en ambas muestras la competencia percibida para el aprendizaje y logro en las matemáticas disminuye significativamente a medida que van avanzando de los primeros cursos de primaria hasta los últimos de secundaria; ello lo relacionan con la actitud de docentes, pues a través de ella, el alumnado percibe las expectativas que sus docentes tienen sobre su logro futuro. Lo anterior, aunado al rendimiento que van obteniendo en la materia, que confirma las expectativas discentes.

En este sentido, Núñez et al. (2005) indican que, una vez perdida la confianza en la propia capacidad, se produce una afectación directa sobre el propio interés por la materia y surgen los sentimientos y emociones negativas y aumenta la ansiedad. Los investigadores indican que, al 
ISSN Electrónico: 2215-3470 DOI: http://dx.doi.org/10.15359/ru.30-1.4
UNICIENCIA Vol. 30, No. 1, pp. 57-84. Enero-Junio, 2016. URL: www.revistas.una.ac.cr/uniciencia Email: revistauniciencia@una.cr

inicio de la escolaridad, la ansiedad no está presente en las actividades escolares, es a partir del segundo ciclo de primaria cuando los niveles de ansiedad se incrementan considerablemente. Además, señalan que tales resultados pueden estar indicando ya, al final del segundo ciclo de primaria, el inicio de la preocupación por el hecho de bajar el rendimiento en esta área.

En Pakistán, Amirali (2010) realizó un estudio cuantitativo con 80 estudiantes de una escuela secundaria de Karachi, en donde el objetivo principal fue explorar las concepciones respecto a la naturaleza de las matemáticas y su actitud hacia el aprendizaje de la disciplina. Para ello elaboró un cuestionario que incluyó preguntas en cuatro áreas: utilidad de las matemáticas, la naturaleza de la asignatura, la actitud hacia esta y ansiedad matemática.

En relación con la utilidad de las matemáticas, Amirali (2010) indica que la mayoría de estudiantes están de acuerdo en que estas se utilizan en la vida cotidiana, desarrollan habilidades para resolver problemas, fortalecen los procesos de pensamiento y ayudan a conseguir buenos puestos de trabajo en el futuro. Al analizar las respuestas relacionadas con la naturaleza, la mayoría señala estar de acuerdo con los enunciados que indican que las matemáticas no se pueden cambiar y que el conocimiento actual de las matemáticas está abierto a revisión o cambio. Con respecto a las actitudes hacia las matemáticas y la ansiedad matemática, se señala que el estudiantado muestra una actitud positiva y, por tanto, su nivel de ansiedad es bajo.

Por su parte, Yara (2009) reporta el resultado de una investigación del tipo descriptiva realizada con 1542 estudiantes de enseñanza secundaria en el sudoeste de Nigeria. A estos estudiantes se les aplicó un cuestionario que se dividió en dos secciones: una que trataba sobre datos biográficos de estudiantes y otra que constaba de 22 ítems (11 redactados en forma positiva y 11 en forma negativa) a los cuales debían responder según su grado de acuerdo o no en una escala de cuatro puntos.

Los resultados mostraron que las actitudes de estudiantes hacia las matemáticas fueron positivas y que la mayoría creía que las matemáticas son un tema que vale la pena estudiar y que puede ayudarle en su carrera profesional. Además, Yara (2009) menciona que la mayoría de estudiantes de la encuesta están de acuerdo en que pueden "hacer matemática", que no representa una materia muy difícil, que hay demasiados hechos que se deben aprender, que el estudio de la disciplina ayuda a desarrollar habilidades de razonamiento y que las matemáticas tienen muchos términos técnicos que son difíciles de recordar.

En Costa Rica, Cubillo et al. (2010) realizaron un estudio entre colegios públicos urbanos con el propósito de estudiar la actitud hacia las matemática en las dimensiones agrado, utilidad, dificultad y ansiedad, analizando si existía diferencia por género, nivel o colegio. La investigación se realizó con un enfoque cuantitativo de tipo descriptivo y aplicaron un diferencial semántico a 3587 estudiantes y un cuestionario con escala tipo Likert de cinco opciones a 1234 estudiantes de las instituciones seleccionadas.

Entre las principales conclusiones que se obtuvieron en el estudio, se destacan que sus participantes presentan una actitud positiva baja hacia las matemáticas a los siguientes aspectos: agradable, bonita, apreciable y atractiva, a la vez que manifiestan una actitud muy positiva hacia las matemáticas como disciplina útil e importante; tienen una actitud negativa hacia las matemáticas en los aspectos dificultad y ansiedad; manifiestan que las matemáticas son difíciles, complicadas, confusas y las califican como una disciplina frustrante y estresante; no hubo diferencia de género en cuanto al agrado manifestado hacia la asignatura. Para ambos géneros las matemáticas son una disciplina complicada, difícil, confusa y estresante, aunque útil e importante. 
Por su parte, Meza y Azofeifa (2011) realizaron, en el año 2010, un estudio cuantitativo en el cantón central de Cartago, cuyos objetivos fueron diagnosticar la actitud hacia las matemáticas de los estudiantes de undécimo año de los colegios de la región, establecer si existen diferencias significativas, según el género y comprobar si existen diferencias significativas, según el colegio al que pertenecen. La investigación se realizó con 727 estudiantes de undécimo año y se aplicó un diferencial semántico.

Las conclusiones reportadas por los investigadores señalan que el estudiantado mostró una actitud positiva moderada acerca de que las matemáticas son una disciplina útil, necesaria, agradable, formativa y aplicable, mientras que para la categoría relevante y entendible esta fue positiva baja. Además, apuntan que mostraron una actitud negativa hacia la disciplina como aburrida, confusa, frustrante, estresante y compleja.

Respecto al género, Meza y Azofeifa (2011) anotan que, en todos los rubros del diferencial semántico, las medias de los hombres son mayores que las correspondientes a las mujeres, y que las diferencias también se presentaron en la clasificación de las siguientes parejas de adjetivos: difícilfácil, aburrida-divertida, confusa-clara, estresante-relajante, irrelevante-relevante e inentendibleentendible, en las cuales las mujeres presentan una actitud más negativa que las de los varones. Reportan, además, las diferencias de actitud, según la institución a la que pertenece el estudiantado.

En esta misma investigación, los autores recomiendan continuar estudios en esta línea orientados al establecimiento de causas para la explicación de las diferencias de actitud entre hombres y mujeres, el desarrollo de estrategias metodológicas para que favorezcan un mejoramiento de la percepción de las matemáticas como una disciplina atractiva y agradable, no frustrante y poco divertida.

\section{Creencias sobre las matemáticas}

Al igual que en el caso anterior, los estudios relacionados con las creencias hacia las matemáticas son extensos. En Estados Unidos, por ejemplo, en el 2010, Stramel llevó a cabo un estudio para investigar las actitudes hacia las matemáticas y las creencias de autoeficacia en esta asignatura de 273 estudiantes de secundaria en una escuela media en el oeste de Kansas. El marco conceptual para este estudio se apoyó en la investigación de Albert Bandura sobre la teoría social cognitiva. El investigador utilizó un diseño mixto, donde aplicó un cuestionario a todos los participantes, realizó observaciones de clase y entrevistó a 18 estudiantes.

Entre los hallazgos cita que el estudiantado atribuye su alta creencia en la autoeficacia en matemáticas al profesorado o a las altas notas que reciben en las tareas diarias, así como en las distintas evaluaciones. Por el contrario, en secundaria tienen una baja creencia en su autoeficacia en esta asignatura, lo hacen cuando se sienten sin éxito o estresados y atribuyen esas creencias a las bajas calificaciones que reciben en las tareas diarias y evaluaciones, así como a la angustia de no entender la materia.

En Chile, Chandía et al. (2006) realizaron un estudio para determinar las creencias de estudiantes y docentes de primer año de cinco establecimientos educacionales de la intercomuna de Concepción, asociadas a la asignatura de matemáticas. Para ello, los investigadores realizaron un grupo focal con estudiantes, aplicaron un cuestionario simple y realizaron entrevistas a profundidad a docentes. En relación con los resultados obtenidos con estudiantes, los autores mencionan y destacan que ninguno considera a las matemáticas como inalcanzable, ni extremadamente complicada y que a muy pocos les es indiferente. A quienes no les gusta la asignatura, argumentan como motivo, que "no la entienden", y lo atribuyen a causas internas ("no pongo atención") o externas ("no le entiendo a la profe"). 
ISSN Electrónico: 2215-3470 DOI: http://dx.doi.org/10.15359/ru.30-1.4
UNICIENCIA Vol. 30, No. 1, pp. 57-84. Enero-Junio, 2016. URL: www.revistas.una.ac.cr/uniciencia Email: revistauniciencia@una.cr

Aunado a lo anterior, Chandía et al. (2006) apuntan que el estudiantado carece de un concepto claro de lo que son las matemáticas y solo centran la atención en su utilidad. Respecto a lo que un buen profesor o profesora debe hacer, señalan, en orden de importancia, que debe establecer un buen ambiente afectivo, tener formación pedagógica idónea, poseer características personales adecuadas al trabajo en un aula y ser matemáticamente competente. Según el estudiantado, el contexto sociocultural no ofrece un impedimento para aprender o para escalar socioculturalmente, aunque indica que sí puede ofrecer ciertas dificultades; considera que si recibe las herramientas necesarias, puede surgir en la vida. En este sentido, varios alumnos indicaron que se sentían insatisfechos por el nivel de exigencia mostrado por el profesorado, pues consideran que ello les coarta sus expectativas futuras.

Con base en los resultados obtenidos con el personal docente, Chandía et al. (2006) apuntan que el hallazgo más relevante de la investigación fue la correlación detectada entre las expectativas de este sobre sus estudiantes y los centros de atención de estos en su labor docente; además, se observó que su visión con respecto a lo que son las matemáticas tiene correlación con el cómo enfoca la enseñanza de la disciplina y también con el cómo el alumnado ve dicha materia. Al analizar la relación entre las creencias de estudiantes y docentes, los investigadores observaron que ciertas creencias estudiantiles podrían tener su fuente de origen en su propio profesorado. Sin embargo, apuntan que con la información disponible es adecuado ofrecer una hipótesis que explique lo anterior y señalan la necesidad de realizar estudios que lo validen.

En España, Gómez-Chacón et al. (2006) realizaron una investigación con 279 estudiantes de tercero de secundaria (149 mujeres y 130 hombres), orientada a la mejora de la práctica educativa, con el propósito de proporcionar información sobre la influencia de las creencias. Para la recolección de los datos, utilizaron un cuestionario (escala de Likert) que aplicaron a estudiantes para el diagnóstico de las creencias; un cuestionario sobre creencias respecto a la educación matemática aplicado al profesorado y se realizaron entrevistas a estos para indagar el rendimiento estudiantil y las dificultades de aprendizaje. La parte cuantitativa se complementó con una metodología cualitativa descriptiva e interpretativa.

La investigación realizada demostró la relación entre las creencias sobre sí mismos (la confianza y la competencia personal en matemáticas), la opción de estudios elegida y el rendimiento; además, verifica la variabilidad según contexto sociocultural (contexto de clase) respecto a las creencias de estudiantes sobre el papel y el funcionamiento del profesorado, sobre el significado y la competencia en matemáticas y sobre las matemáticas como actividad social. En el estudio se encontró que el estudiantado percibe las dimensiones cognitiva, motivadora y afectiva que sus docentes utilizan en su estilo de enseñanza en el aula; y que, en algunos casos, tanto el personal docente como su metodología de enseñanza repercuten en las creencias y el comportamiento del alumnado.

Por su parte, Lazim, Abu y Wan (2004) realizaron, en Malasia, un estudio estadístico para investigar las creencias de estudiantes sobre las matemáticas. Para esto elaboraron un instrumento con consideraciones teóricas con puntos de vista acerca de las matemáticas y los componentes de las creencias en las interacciones entre profesorado y estudiantado. El instrumento fue aplicado a 215 estudiantes de tres escuelas secundarias. Entre los resultados obtenidos por los investigadores se señala aceptaron positivamente la importancia del personal docente en el proceso de aprender matemáticas. De esta forma, la importancia de las matemáticas en la vida cotidiana y el rol docente en los procesos de aprendizaje se ven como fundamentales en las 
creencias sobre la disciplina. Respecto a cómo se deben aprender las matemáticas, los grupos de estudiantes participantes en el estudio señalan la importancia de los ejercicios y las prácticas.

A nivel nacional, Chacón y Sánchez (2000) llevaron a cabo un estudio cualitativo titulado Reflexiones acerca de las creencias asociadas a la aversión hacia la asignatura de matemática, en el cual trabajaron con cuatro estudiantes de secundaria. Entre los hallazgos obtenidos en este estudio se destaca que la aversión hacia esta disciplina puede entorpecer el proceso de aprendizaje; además, que el estudiantado tiende a creer que las matemáticas que reciben son poco útiles en la vida, difíciles, aburridas y que se imparten de manera monótona. Consideran que el gusto por esta es innato.

Además, se menciona que entre las razones que pueden condicionar la aversión hacia esta materia están aspectos académicos, socioculturales, de significado y calidad de los aprendizajes, estructura conceptual de la asignatura, escasa conexión de las experiencias de aprendizajes con la vida cotidiana, poco valor práctico, contenidos de difícil comprensión, las relaciones establecidas entre docentes y estudiantes, percepción negativa del alumnado respecto al profesorado y sobre sí mismo y deficiencias en los métodos de enseñanza.

En el 2003, Abarca, como parte de su tesis doctoral en educación en la Universidad Estatal a Distancia, realizó el estudio denominado Imágenes de los alumnos y alumnas de sétimo año acerca de las matemáticas: Un estudio de casos. La pregunta de investigación fue: ¿Cuáles son las imágenes acerca de las matemáticas desarrolladas por alumnos y alumnas de dos secciones de sétimo año de un colegio público de San José? El estudio se desarrolló desde un abordaje cualitativo.

Entre los resultados más sobresalientes de la investigación de Abarca (2003) se pueden mencionar que las imágenes que presenta el alumnado hacia las matemáticas poseen una gran carga emocional; en el caso de imágenes desfavorables, es evidente la somatización que hacen, pudiendo encontrarse expresiones fisiológicas localizadas en distintas partes del cuerpo como la cabeza, las náuseas, mareo y malestar generalizado; la naturaleza de las imágenes es reduccionista, pues poseen concepciones fragmentarias e incompletas de la asignatura; sus experiencias escolares parecen haber formado imágenes de las matemáticas alejadas de su vida personal; la escuela no aparece como un espacio dinamizador del conocimiento matemático, lo cual enfatiza en metodología rutinarias y poco interesantes; las imágenes desfavorables hacia las matemáticas adquiridas durante la educación primaria, continúan influyendo negativamente durante la secundaria; el estudiantado tiene un papel receptivo, de acumulador de información, con poca participación en las decisiones curriculares que se toman en el aula; la familia aparece implícitamente como un elemento influyente en la formación de imágenes hacia esta disciplina.

Por su parte, Mora y Barrantes (2008), con el propósito de contrastar los resultados acerca de las creencias y concepciones sobre las matemáticas que poseen docentes y estudiantes de otros países y las que tienen estas mismas poblaciones en Costa Rica, realizaron un estudio con estudiantes de octavo y décimo año y profesorado de matemáticas de esos niveles de estudio. Para ello, aplicaron un cuestionario a 1240 estudiantes (640 estudiantes de octavo año y 600 de décimo; 601 masculinos y 639 femeninas) y a 36 docentes (15 hombres y 21 mujeres). El instrumento aplicado a estudiantes constaba de cinco partes: información general, qué es saber matemáticas, qué es un problema matemático, libros de texto y las matemáticas y los problemas matemáticos en la clase. La sección denominada qué es saber matemáticas estaba enfocada a determinar algunas concepciones que, sobre las matemáticas, tienen. 
ISSN Electrónico: 2215-3470 DOI: http://dx.doi.org/10.15359/ru.30-1.4
UNICIENCIA Vol. 30, No. 1, pp. 57-84. Enero-Junio, 2016. URL: www.revistas.una.ac.cr/uniciencia Email: revistauniciencia@una.cr

El instrumento suministrado a profesores y profesoras constaba de las siguientes secciones: información general, propósito de la enseñanza aprendizaje de las matemáticas en la educación secundaria, qué es un problema matemático, problemas matemáticos en la enseñanza de las matemáticas y programas y libros de texto.

El denominado propósito de la enseñanza aprendizaje de las matemáticas en la educación secundaria tenía como objetivo determinar algunas creencias del profesorado con respecto a la enseñanza y aprendizaje de esta disciplina. Entre los resultados reportados por los investigadores se destaca que la visión predominante entre el grupo encuestado de docentes, respecto a la enseñanza de las matemáticas, está ligada a una concepción constructivista del proceso, donde la mayoría piensa que debe prepararse al estudiantado para enfrentarse a la resolución de problemas de diferentes tipos. En contraposición a esto, Mora y Barrantes (2008) indican que aunque el estudiantado no muestra una concepción clara acerca de las matemáticas, cabe señalar que se da una cierta preponderancia de la visión algorítmica.

Los autores indican que los resultados anteriores parecen ser contradictorios pues, según diversos estudios, la visión estudiantil está fuertemente influenciada por el trabajo en la clase. Sin embargo, argumentan que los datos obtenidos reflejan la opinión del personal docente y no necesariamente lo que este hace en clase; es decir, que aunque piense que lo mejor es una aproximación constructivista en el proceso de enseñanza y aprendizaje de las matemáticas, por diversas razones su actuar está más dirigido por lo algorítmico.

Adicional al trabajo anterior, Barrantes (2008) reporta los resultados de una investigación realizada con estudiantes de octavo y décimo año de la enseñanza media de nuestro país. Para la muestra se seleccionaron 21 instituciones educativas de enseñanza media pertenecientes a cuatro direcciones regionales educativas. En cada institución se seleccionó un grupo de octavo y otro de décimo año. Se aplicó un instrumento a cada estudiante de cada uno de los grupos seleccionados. En total respondieron la encuesta 1240 estudiantes; de ellos, 640 estudiantes de octavo año y 600 de décimo. En cuanto a género, 601 masculinos y 639 femeninas.

Entre los resultados destacados por el investigador se cita la tendencia observada y preponderante a considerar que saber matemáticas significa poder resolver cualquier problema relacionado con el tema en estudio; quienes creen que saber matemáticas es conocer de memoria muchos procedimientos útiles para resolver ejercicios piensan, mayoritariamente, que un problema matemático es un ejercicio asignado por el profesor para saber si el estudiante ha aprendido una definición, una fórmula o un procedimiento; hay una correlación positiva entre las creencias de que un problema solo tiene una respuesta correcta y la de que al resolver un problema todos los datos en el enunciado son necesarios o relevantes; además, que se resuelve solo efectuando operaciones, que resolver un problema matemático es descubrir cuál es la operación correcta, la cual se descubre analizando las palabras clave del enunciado; quienes piensan que saber matemáticas es aplicar procesos creativos a diferentes situaciones creen, mayoritariamente, que un problema es una situación propuesta por el profesor para que el estudiante desarrolle nuevas habilidades.

\section{Actitudes y creencias hacia las matemáticas}

De acuerdo con la bibliografía revisada, ha habido investigaciones que han tratado ambos aspectos en forma conjunta. Es importante señalar que a nivel nacional no se encontró un estudio abarcador de ambos constructos en forma conjunta en estudiantes de secundaria. A 
nivel internacional, en los últimos años, se reporta el realizado por Eleftherios y Theodosios (2007) en Grecia.

Los investigadores realizaron un estudio cuyo objetivo era analizar las actitudes y creencias estudiantiles sobre las matemáticas, si estas afectan su capacidad matemática y si existen diferencias en las creencias y las actitudes de estudiantes respecto a su situación social, género y tipo de escuela. La muestra de este tratado fue de 1645 estudiantes de secundaria de distintas instituciones de Atenas. Los resultados clarifican la estructura de las actitudes y creencias sobre las matemáticas y la forma en que influye en el desempeño matemático y habilidad para entender las pruebas que se realizan en la disciplina. Eleftherios y Theodosios (2007) indican que estas son independientes del estado socioeconómico, aunque señalan que otros investigadores afirman que las creencias cambian de país a país.

El estudio dejó en claro que la variable "tipo de la escuela" (público en general, privado y técnicas públicas) influye en las actitudes y creencias del alumnado. Estudiantes de las escuelas públicas y privadas, en general, tenían menos dificultad en matemáticas que los de los técnicos, lo cual, según Eleftherios y Theodosios (2007), es una consecuencia esperada del hecho de que en las escuelas técnicas el nivel cognitivo de estudiantes es más bajo que los de secundaria general.

El estudiantado de escuelas privadas cree más firmemente en la utilidad de las pruebas y las matemáticas, en general, que el de las públicas y técnicas. Por su parte, el de las escuelas técnicas cree más firmemente que la comprensión matemática se logra a través del manejo de los procedimientos. Respecto al género, los investigadores reportan que la creencia de que la comprensión matemática se logra a través del manejo de los procedimientos es mayor en el género femenino.

Eleftherios y Theodosios (2007) reportan que "el amor" por las matemáticas se correlaciona positivamente con un alto rendimiento y habilidad en la disciplina y resaltan los resultados de su investigación, los cuales concuerdan con la idea de que las creencias son una variable oculta en la educación matemática, así como las actitudes y creencias influyen en el rendimiento y la capacidad matemática.

\section{La influencia del docente de matemáticas}

Los resultados de las distintas investigaciones en el campo de las actitudes y creencias hacia las matemáticas permiten concluir que las experiencias de una persona respecto a la enseñanza y aprendizaje de la disciplina, determinan, en parte, la forma en que esta es abordada por el individuo y cómo "se enfrenta" a las distintas actividades relacionadas con ella.

El rendimiento académico en matemáticas ha sido un tema de preocupación por parte de todos los actores relacionados con el proceso de enseñanza y aprendizaje de la disciplina. En este sentido, Gil, Blanco y Guerrero (2005) señalan que los altos índices de fracaso escolar en matemáticas exigen el estudio de la influencia de los factores afectivos y emocionales en el aprendizaje de la disciplina, ya que podrían explicar la ansiedad que experimenta el alumnado hacia ella, así como su sensación de malestar, frustración, inseguridad, bajo autoconcepto, entre otros, que le impide su éxito y eficacia.

Aunado a lo anterior, es necesario considerar que la enseñanza y el aprendizaje de las matemáticas no suceden en un ámbito aislado y neutral, pues está influenciado por el contexto en que se desenvuelve y el comportamiento humano de sus participantes (Gómez, 2000). En este sentido, la autora destaca que el profesor juega un modelo de actuación que tiene un papel importante en la formación de actitudes, creencias y en la resolución de problemas. 
ISSN Electrónico: 2215-3470 DOI: http://dx.doi.org/10.15359/ru.30-1.4
UNICIENCIA Vol. 30, No. 1, pp. 57-84. Enero-Junio, 2016. URL: www.revistas.una.ac.cr/uniciencia Email: revistauniciencia@una.cr

La labor docente en el aula implica tomar una serie de decisiones, actitudes y creencias que se traducen en sus ideas sobre qué son, para qué sirven y cómo se aprenden las matemáticas (Gómez, 2000). Estas influyen directamente en sus estudiantes y deben ser tomadas en cuenta y, sobre todo, analizadas para entender las distintas situaciones que suceden en el aula, los comportamientos del alumnado hacia la materia, hacia el mismo profesorado y la imagen que poseen de este.

Las investigaciones realizadas en el campo de las actitudes y creencias de estudiantes hacia las matemáticas se han centrado, la mayoría de ellas, en especificar estas y realizar algunas correlaciones entre distintos aspectos. También han recalcado la importancia de que el personal docente considere la dimensión afectiva en los procesos de enseñanza y aprendizaje de las matemáticas. Aunque el factor docente se ha mencionado en algunas investigaciones, muy pocas de ellas han profundizado en la relación de la tendencia didáctica de este con la formación de las actitudes y creencias hacia las matemáticas que poseen sus estudiantes, aspecto que surge relevante, pues afecta su aprendizaje.

En este sentido, Akay y Boz (2010), basados en los resultados de distintas investigaciones, indican que docentes con baja autoeficacia en matemática tienden a verse a sí como docentes autoritarios y afectan negativamente las actitudes de sus estudiantes, produciendo inseguridad; mientras que docentes con una alta autoeficacia en la disciplina, se sienten orgullosos porque pueden ayudar a sus estudiantes de bajo rendimiento en su aprendizaje.

Sobre el personal docente de matemáticas, Martínez (2008) indica que este, para poder conducir con éxito el proceso de enseñanza, aprendizaje y evaluación de las matemáticas, requiere conocer bien los contenidos a enseñar y saber transponerlos, didácticamente, en forma adecuada; saber elegir las mejores estrategias para evaluarlos y considerar el afecto de sus estudiantes en el desarrollo de estos procesos. De esta forma, se señala que un personal docente de matemáticas que no sea competente en la materia no podría dar confianza a sus estudiantes y establecer una autoridad en el aula que se base en el respeto (Akay y Boz, 2010).

Esta competencia en matemáticas para enseñar la disciplina implica considerar el componente afectivo y responder a las demandas y necesidades estudiantiles. Por ello, Bazán y Aparicio (2006) señalan que la afectividad siempre aparece relacionada con la educación, donde el papel de quien educa es considerado importante y suele relacionarse con cuestiones de la afectividad.

En este sentido, Chandía et al. (2006) apuntan que varias investigaciones y personal académico han señalado la necesidad de una entrega emotiva por parte del profesorado de matemáticas, de forma tal que el estudiantado sea concebido como una persona y no solamente se considerare aquella parte de este en la que adopta su función exclusiva de aprendiz.

En el aula tanto estudiantes como docentes construyen actitudes positivas, neutras o negativas hacia las matemáticas, las cuales pueden conducir a que se "enamoren" de la disciplina y permitan la construcción de ámbitos de cariño, estimación y reconocimiento; o bien, que conduzcan a la ausencia de interés, atención y preocupación por las matemáticas e, incluso, el rechazo hacia estas (Martínez, 2008).

Por ello, las reacciones valorativas hacia las matemáticas, hacia quién y cómo la enseña, hacia cómo se aprende o hacia quién y cómo se evalúa muchas veces son producto de las vivencias que el estudiantado ha experimentado como miembro de determinadas comunidades, donde la disciplina ha sido considerada como una de las más impopulares asignaturas del currículo (Martínez, 2008). Por esto, Mora y Barrantes (2008) recalcan la influencia del personal docente, quien transmite al estudiantado parte de su concepción y experiencias vividas y promoverá en este una forma particular de abordar el estudio de las matemáticas. 
En este sentido, Domínguez y Jarero (2010) indican que si partimos del hecho de que las actitudes y creencias de estudiantes son acogidas por el profesorado con el cual ha interactuado a lo largo de su experiencia escolar por medio del tipo de enseñanza recibida, se podría concluir que este último grupo posee creencias y prácticas docentes que distan mucho de la tendencia investigativa. A raíz de esto, los autores señalan que se requiere una formación docente en la que se enfatice la necesidad de cambiar el tipo de práctica, esto a través de la concientización del impacto que se causa en los aspectos afectivos del discente, relacionados con las matemáticas.

Como parte de esta concienciación orientada a un "cambio en la práctica docente" se debe considerar la influencia que el personal docente posee en sus estudiantes, muchas veces inconsciente, con el fin de que los aspectos que surjan de este puedan ser reforzados o cambiados con el propósito de favorecer el aprendizaje de aquellos y responder a sus necesidades y particularidades. Debido a que "No es posible pensar que el profesor pasa de ser estudiante a ser profesor por un proceso de formación puntual, sino que se ve sumergido en un proceso de desarrollo profesional continuo, en el que va atravesando diversos papeles y momentos" (Cardeñoso, Flores y Azcárate, 2001, p. 234), los autores indican como una de las tareas más importantes que debe asumir la educación matemática, el desarrollo profesional del profesorado $y$, en consecuencia, promover procesos instructivos que lo fomenten.

Para llevar a cabo esta tarea se necesitan, además, investigaciones que suministren información necesaria para diseñar estrategias de formación y observar las dimensiones y aspectos que la caracterizan. Por esto, se hace necesario profundizar en la relación existente entre el profesorado de matemáticas y las actitudes y creencias hacia la disciplina de estudiantes, con el propósito de identificar elementos de la tendencia didáctica, y del personal docente mismo, los cuales pueden ser cambiados e incorporados en los planes de formación docente para facilitar el abordaje del aspecto emocional de sus estudiantes $y$, por ende, influenciar en forma positiva en el aprendizaje de las matemáticas.

\section{La tendencia didáctica y práctica docente del profesor de matemáticas}

El rol docente en la enseñanza de las matemáticas ha sido un aspecto que se ha estudiado en algunas investigaciones. La influencia que este ostenta es un hecho que resulta relevante como un elemento que afecta, positiva o negativamente, el aprendizaje de estudiantes.

La práctica docente del profesorado de matemáticas, enmarcada dentro de una tendencia didáctica que la rige, se basa en una visión particular de la metodología a emplear, el sentido de la asignatura, concepción del aprendizaje, papel del alumnado, rol del profesorado y estrategias de evaluación a utilizar (Contreras 1998).

Las prácticas docentes son las acciones orientadas que lleva a cabo el docente producto de la reflexión, la explicación y la discusión de su experiencia educativa en una escuela particular, la cual le da contexto y sentido a su quehacer. El docente transforma su experiencia en conocimientos a través del análisis y la sistematización de la misma, y estos conocimientos orientan sus acciones convirtiéndose en prácticas. (Serres, 2010, p. 1055).

En este sentido, en el proceso de planificación de las actividades para la clase de matemáticas, la interpretación subjetiva de las nociones matemáticas como objetos de enseñanza y aprendizaje, por parte del profesorado, condicionan el diseño de estas. La experiencia previa del personal docente 
ISSN Electrónico: 2215-3470

DOI: http://dx.doi.org/10.15359/ru.30-1.4
UNICIENCIA Vol. 30, No. 1, pp. 57-84. Enero-Junio, 2016.

URL: www.revistas.una.ac.cr/uniciencia Email: revistauniciencia@una.cr

es un factor que incide en dicho proceso, por lo que existe relación entre aspectos de la práctica del profesorado y la manera en que este define una determinada actividad en el aula (Llinares, 2000).

Al respecto, Serres (2010) apunta que el personal docente, por medio de su experiencia en el aula y con base en las estrategias metodológicas que emplea, adquiere conocimiento sobre cómo aprenden sus educandos y el tipo de actividades que se pueden desarrollar según el contexto en el que se realiza el proceso de enseñanza y aprendizaje, los recursos por utilizar y las técnicas de evaluación que se podrían emplear.

La actividad que los profesores desarrollan en sus aulas parece estar orientada por sus concepciones. Éstas son como un filtro que regula el estilo personal de enseñar y las decisiones que se toman durante la instrucción: las opciones que se toman respecto al contenido, la metodología o los recursos a emplear o los distintos momentos de la evaluación, su propia estructura y las interacciones educativas, si entendemos todos estos elementos como integrantes de un complejo marco de relaciones entre el contenido matemático, los alumnos y el profesor. (Contreras, 2009, p. 17).

De acuerdo con Plata y Trillo (2001), la tendencia más común en la práctica de los docentes de matemáticas es aquella que propicia que el saber, en la disciplina, significa recordar y aplicar las reglas correctas. Estas ideas, señalan los autores, son transmitidas por los profesores y profesoras a sus estudiantes incluso de manera inconsciente.

Sin embargo, también mencionan que existe un amplio consenso en la educación matemática respecto a una concepción dinámica de la disciplina, donde el proceso de construcción del conocimiento posee un papel relevante; otras tendencias, por su parte, ven la enseñanza de la asignatura como una actividad donde es necesario implicar al estudiantado en la búsqueda de soluciones a los problemas.

Distintas investigaciones relacionadas con la práctica educativa del profesorado de matemáticas señalan que, entre los factores influyentes, están sus características docentes, sus creencias y concepciones hacia la disciplina, la forma de enseñarla y de aprenderla, aspectos que no necesariamente están relacionados con las características de los educandos o las condiciones institucionales (Báez, Cantú y Gómez, 2007).

Entre las investigaciones que se han realizado ligadas con las prácticas del profesorado de matemáticas, se puede citar la llevada a cabo por Plata y Trillo (2001), en España, con 21 profesores. Esta se orientó a conocer cómo el personal docente entendía la enseñanza, cuáles eran sus concepciones sobre las matemáticas y sobre el modo como aprende el alumnado, cómo entendían la evaluación y cuál era la opinión que poseían sobre su propia práctica. Los datos se obtuvieron por medio de entrevistas.

De la información recopilada, los investigadores destacan la escasa atención que el profesorado dedica a la reflexión acerca del significado de las matemáticas y su contribución a la formación de los educandos, pues se da por un hecho que son fundamentales en la formación de cualquier persona, aunque esto no se vea reflejado en su práctica educativa; además, destacan que el uso de la resolución de problemas como estrategia metodológica es poco utilizada en las lecciones; enfatizan que, para el cuerpo docente, enseñar es transmitir información y que aprender es saber hacer los ejercicios propuestos. Por tal razón, una práctica frecuente en la 
disciplina es que los conceptos se presenten desligados del contexto en el cual se desarrolla cada estudiante, con poca o ninguna relación con otras áreas, lo que no facilita la comprensión de estos. Respecto a la evaluación, esta fue concebida como sinónimo de examen.

En ese mismo país, Fuentes, García y Martínez (2009) realizaron un estudio con 83 docentes de matemática en formación, cuyo propósito fue conocer qué modelos didácticos consideraban como más adecuados para la enseñanza. La información se recolectó por medio de cuestionarios.

Los resultados obtenidos apuntan a que defienden una posición constructivista para la enseñanza de la disciplina, aunque no poseen una idea clara de lo que esta significa ni de los fundamentos epistemológicos, psicológicos y pedagógicos. Esto conlleva a que, en algunos casos, las actividades que desarrollan en el aula no sean coherentes con lo que creen que es lo ideal y se orienten a esquemas de enseñanza tradicionales.

En Latinoamérica, en el año 2007, Báez et al. (2007) realizaron un estudio para determinar cuáles eran las creencias y concepciones del profesorado de matemáticas en el nivel medio superior del estado de Yucatán, México, y qué era lo característico de las prácticas docentes en el aula. La investigación realizada fue cualitativa y se utilizaron para la recolección de los datos una encuesta, la observación no participante y entrevistas.

Los resultados mostraron que el personal docente reconoce la importancia de las matemáticas en la sociedad, apunta que uno de los factores influyentes para la alta reprobación que hay en la materia es la predisposición del alumnado hacia ella y cree que los educandos no encuentran la utilidad práctica de esta. Sobre este último aspecto, Báez et al. (2007) indican que este está relacionado directamente con el profesorado, pues una de sus funciones debe ser mostrarles a sus estudiantes la utilidad de la disciplina, lo que se podría interpretar como una debilidad del proceso de enseñanza.

El personal docente, además, considera que su grupo juega un importante papel en el proceso de enseñanza y aprendizaje de la disciplina, pues tiene a cargo ayudar a sus estudiantes a resolver problemas, por lo cual reconoce que todo profesor o profesora debe poseer una buena formación facilitadora de la implementación y creación de estrategias didácticas que coadyuven en el aprendizaje de sus educandos.

Respecto a la tendencia didáctica, Báez et al. (2007) señalan que, con base en los resultados obtenidos con las encuestas, el profesorado manifiesta, con mayor frecuencia, la investigativa, aunque la práctica contradice lo anterior, al observarse una tendencia tradicional-tecnológica.

En México otros investigadores, como Aparicio, Jarero, Ordaz y Sosa (2009), llevaron a cabo una investigación con docentes para analizar la relación del discurso matemático escolar y las prácticas docentes en las lecciones de la disciplina. El diseño del estudio fue cualitativo y para la recolección de los datos utilizaron la observación, un cuestionario y entrevistas.

Los investigadores observaron que el profesorado realiza en el aula actividades previamente planificadas; pero no creadas por ellos, pues eran tomadas de libros de texto. Además, señalan que el personal docente concibe la disciplina como una organización de conceptos y reglas que deben ser enseñadas y ejemplificadas para que sus estudiantes adquieran dicho conocimiento.

Respecto del discurso escolar, los investigadores mencionan la existencia de una brecha entre lo que se pretende realizar desde los programas de estudio y lo que se realiza en el aula, pues "la concepción que se tiene de qué es la matemática y cómo enseñarla, difiere entre lo plasmado en los programas de matemáticas y las creencias de los profesores" (Aparicio et al., 2009, p. 69).

Por su parte, Lebrija, Flores y Trejos (2010) realizaron un estudio con 41 docentes de Panamá, cuyo objetivo fue conocer y analizar las creencias hacia el aprendizaje y la enseñanza, en general, 
ISSN Electrónico: 2215-3470 DOI: http://dx.doi.org/10.15359/ru.30-1.4
UNICIENCIA Vol. 30, No. 1, pp. 57-84. Enero-Junio, 2016. URL: www.revistas.una.ac.cr/uniciencia Email: revistauniciencia@una.cr

y el aprendizaje y la enseñanza de las matemáticas, de profesores de nivel medio y premedio, así como la relación de estas creencias con los años de experiencia. Para la recolección de los datos utilizaron dos cuestionarios titulados Inventario de prácticas centradas en el aprendiz y Creencias hacia el aprendizaje, la ciencia matemática y estrategias de enseñanza-aprendizaje.

En este sentido, los resultados obtenidos por los investigadores mostraron que el profesorado posee una visión tradicional de las matemáticas y su enseñanza; además, señalan la promoción de un aprendizaje más centrado en aspectos algorítmicos, que dejan de lado la resolución de problemas. Asimismo, destacan que, aunque posee creencias desfavorables respecto a sus educandos, muestra preocupación por atender sus aspectos socioafectivos.

Además de los resultados anteriores, Lebrija et al. (2010) apuntan que, con respecto a la reprobación, se obtuvo un dato contradictorio por parte de docentes, pues aunque muestran una mayor preocupación por sus educandos, conforme aumentan los años en servicio, poseen una opinión negativa relacionada con aquellos que no logran comprender.

En Costa Rica, Moreira (2001) efectuó un estudio en el cual realizó un acercamiento inicial a las percepciones de cinco docentes de matemáticas de secundaria sobre su formación y la posible vinculación con sus articulaciones metodológicas y con las actitudes de los estudiantes. A la vez, ahondó en la identificación de las creencias que moldearon la actitud hacia las matemáticas en aquel estudiantado que interactuaba con este personal docente.

Entre los resultados obtenidos por la investigadora se señala que las articulaciones metodológicas docentes no se generaron de un proceso de autorreflexión y concienciación, ya que su forma de enseñar se consideraba como el reflejo de algún profesor o profesora de matemática que había tenido una influencia. De acuerdo con Moreira (2001), este hecho se fortaleció por la percepción de que las materias de pedagogía, en su proceso de formación, no fueron significativas, no estaban contextualizadas en su realidad y fueron valorabas como poco útiles para su trabajo en el aula.

De acuerdo con la autora, la metodología empleada por este grupo de docentes de matemáticas es caracterizada como tradicional, donde el profesorado es el que posee el conocimiento y, por ende, quien razona, explica, ejemplifica, resuelve y posee el criterio para decidir qué es correcto y que no. Por lo tanto, el estudiantado posee un papel pasivo en su aprendizaje y se concibe como un receptor de conocimiento.

En las lecciones de matemáticas no existieron espacios para que sus estudiantes desarrollaran sus estructuras cognitivas, por lo que las actividades orientadas a la reflexión, experimentación y comparación estuvieron ausentes. Moreira (2001) destaca que la metodología empleada no contribuyó a cambiar las creencias y actitudes de estudiantes hacia la materia, pues se fortaleció la imagen de esta como compleja, abstracta y que demanda de un gran esfuerzo para un insuficiente conocimiento.

Con base en los resultados obtenidos, Moreira (2001) señala que es imperativo implementar en la enseñanza de las matemáticas, alternativas para generar un cambio. Entre las estrategias que propone están la creación de espacios lúdicos y el desarrollo de actividades que potencien la habilidad heurística, el razonamiento e integren los intereses y necesidades de los educandos.

Es evidente que lo que el profesorado cree, siente y piensa que posee una influencia directa en el tipo de enseñanza que realiza en el aula. En este sentido, Contreras (2009) apunta: 
Lo que un profesor cree sobre la enseñanza y el aprendizaje de la matemática y lo que un profesor conoce del contenido, métodos y materiales disponibles para enseñar matemáticas influye en sus decisiones relativas a la instrucción. De esta forma, una determinada concepción sobre la Matemática y/o la Educación Matemática condiciona e incluso podría determinar la interpretación y toma de decisiones sobre las concepciones, errores de aprendizaje u obstáculos epistemológicos de los alumnos, orientaría una determinada opción de selección del contenido o búsqueda de situaciones didácticas y permitiría o justificaría el marco de negociación (implícito o explícito) de un determinado contrato didáctico (Contreras, 2009, p. 17).

La influencia de cada docente en el proceso de enseñanza y aprendizaje de la disciplina es un aspecto que debe ser tomado en cuenta en la educación matemática, pues, como señala Contreras (2009) y Báez et al. (2007), la persona docente, ya sea de forma consciente o inconsciente, comunica a sus estudiantes información con base en sus propias experiencias, ya sea como producto de su labor diaria o de sus vivencias como estudiantes, y desarrollan ideas respecto a cómo enseñar los contenidos matemáticos, resolver problemas, y generar aprendizaje.

\section{Discusión final}

A partir de las investigaciones reportadas y lo expresado por algunos autores y autoras, es posible observar la importancia que el estudio de las actitudes y creencias hacia las matemáticas ha tenido como campo de investigación tanto a nivel nacional como internacional. Las investigaciones realizadas, en su mayoría, se han enfocado en el estudiantado como sujetos de investigación y han sido realizadas por docentes de distintas áreas, especialistas en matemática y docentes de matemáticas, tanto a nivel de secundaria como a nivel universitario.

Han sido numerosas las publicaciones efectuadas en este campo y que han determinado la influencia de las actitudes y creencias hacia las matemáticas con el rendimiento académico estudiantil, la escogencia de una carrera universitaria, su grado de ansiedad, motivación, desempeño en la disciplina y expectativas a futuro.

También han determinado que el contexto, la familia y el personal docente afectan la formación de determinadas actitudes y creencias. Sobre este último, se ha indicado que posee un papel determinante según sus propias actitudes y creencias hacia las matemáticas, la metodología utilizada para impartir sus lecciones, expectativas de sus estudiantes y su interacción con ellos. Según las investigaciones consultadas, el enfoque predominante ha sido el cuantitativo, con la técnica de encuesta como la principal en la mayoría de los casos. El enfoque cualitativo ha sido utilizado en los diseños mixtos para profundizar en aspectos obtenidos del análisis de los datos cuantitativos en un mismo estudio o en estudios previos.

Sin embargo, la mayoría de las investigaciones se han centrado en determinar las actitudes y creencias hacia las matemáticas y han establecido algunas correlaciones, pero pocas reportan haber indagado sobre la forma en que algunos elementos influyen en la formación de estas. Respecto al papel docente, aunque se ha determinado su influencia y contradicciones entre lo que "piensa y hace en el aula", poco se ha estudiado sobre cómo este es concebido por el estudiantado a partir de las actitudes y creencias hacia la disciplina o cómo influye su tendencia didáctica en la formación de algunas actitudes y creencias del alumnado hacia las matemáticas.

Es posible determinar que son pocas las investigaciones que, aunque señalan la importancia de incorporar el componente afectivo en sus planes de estudios, presentan acciones concretas 
ISSN Electrónico: 2215-3470

DOI: http://dx.doi.org/10.15359/ru.30-1.4
UNICIENCIA Vol. 30, No. 1, pp. 57-84. Enero-Junio, 2016.

URL: www.revistas.una.ac.cr/uniciencia Email: revistauniciencia@una.cr

para ello. Por esta razón se hace indispensable conocer cómo están relacionados los factores asociados con el contexto familiar, contexto institucional, relaciones interpersonales de estudiantes y el proceso educativo con el origen de las actitudes y creencias estudiantiles.

En el caso particular del personal docente, es necesario conocer cómo se relaciona su tendencia didáctica con la formación de las actitudes y creencias hacia las matemáticas de sus estudiantes, con el objetivo de realizar una revisión de esta y de las acciones que realiza en el aula, que brinde elementos para ser incorporados en los planes de estudios encargados de formar a estos grupos profesionales, con el propósito de influir positivamente en la formación de actitudes y creencias de sus estudiantes y, por ende, en su desempeño en la materia.

Muchos de los problemas que enfrenta la enseñanza de las matemáticas podrían tener sus raíces en aspectos eminentemente afectivos de estudiantes y docentes. Conocer la relación del profesorado de matemáticas y la formación de las actitudes y creencias hacia la disciplina por parte de estudiantes permitirá establecer estrategias para propiciar un cambio en aquellos aspectos influyentes de manera negativa hacia el desarrollo de estas y, por ende, la enseñanza y aprendizaje de la disciplina.

\section{Referencias}

Abarca, S. (2003). Imágenes de los alumnos y alumnas de sétimo año acerca de las matemáticas: Un estudio de casos. (Tesis de doctorado) Universidad Estatal a Distancia. San José, Costa Rica.

Akay, H., \& Boz, N. (2010). The Effect of Problem Posing Oriented Analyses-II Course on the Attitudes toward Mathematics and Mathematics Self-Efficacy of Elementary Prospective Mathematics Teachers. Australian Journal of Teacher Education, 35(1). Recuperado de doi http://dx.doi.org/10.14221/ajte.2010v35n1.6

Amirali, M. (2010). Students' Conceptions of the Nature of Mathematics and Attitudes towards Mathematics Learning. Journal of Research and Reflections in Education, 14(1), 27-41. Recuperado de http://www.ue.edu.pk/JRRE/journal archive.asp

Aparicio, E., Jarero, M., Ordaz, M., \& Sosa, L. (2009). Discurso y práctica docente en matemáticas: Un estudio exploratorio en bachillerato. Revista Iberoamericana de Educación Matemática, 18, 58-72.

Armenteros, B. (2009). Imagen social de las matemáticas. Las matemáticas como elemento de exclusión. Revista digital Enfoques Educativos, 30, 20-24. Recuperado de http://www.enfoqueseducativos. es/enfoques/enfoques 30.pdf

Báez, M., Cantú, C., \& Gómez, K. (2007). Un estudio cualitativo sobre las prácticas docentes en las aulas de matemáticas en el nivel medio (Tesis de licenciatura). Universidad Autónoma de Yucatán. Mérida, Yucatán, México.

Barrantes, H. (2008). Creencias sobre las matemáticas en estudiantes de la enseñanza media costarricense. Cuadernos de Investigación y Formación en Educación Matemática, Año 3, (4), 71-81.

Bazán, J., \& Aparicio, A. (2006). Las actitudes hacia la matemática-estadística dentro de un modelo de aprendizaje. Revista Semestral del Departamento de Educación, XV(28), 1-12.

Belbase, S. (2010). Images, Anxieties and Attitudes toward Mathematics. Recuperado de http://www.eric. ed.gov.una.idm.oclc.org/contentdelivery/servlet/ERICServlet?accno=ED547269

Briley, J., Thompson, T., \& Iran-Nejad, A. (2009). Mathematical Beliefs, Self-Regulation, and Achievement by University Students in Remedial Mathematics Courses. Research in the schools, 16(2), 15-28.

Candia, P. (2009). Actitud hacia las matemáticas en alumnos de ingeniería de tercero y quinto semestres del ITESCA. Ponencia: X Congreso Nacional de Investigación Educativa. Área 5: Educación y Conocimientos Disciplinares. Recuperado de http://www.comie.org.mx/congreso/memoriaelectronica/v10/ pdf/area_tematica_05/ponencias/0310-F.pdf 
UNICIENCIA Vol. 30, No. 1, pp. 57-84. Enero-Junio, 2016.

ISSN Electrónico: 2215-3470

URL: www.revistas.una.ac.cr/uniciencia

Email: revistauniciencia@una.cr

Cardeñoso, J., Flores, P., \& Azcárate, P. (2001). El desarrollo profesional de los profesores de matemáticas como campo de investigación en educación matemática. En P. Gómez; L. Ricos (Eds.), Iniciación a la investigación en didáctica de la matemática. Homenaje al profesor Mauricio Castro. pp. 233-244. Granada: Editorial Universidad de Granada.

Chacón, Y., \& Sánchez, M. (2000). Reflexiones acerca de las creencias asociadas con la aversión hacia la asignatura de matemáticas: Estudio con énfasis cualitativo en el comportamiento de cuatro estudiantes del Colegio Ricardo Fernández Guardia (Tesis de Licenciatura). Universidad Nacional. Heredia, Costa Rica.

Chandía, E., Quiroga, F., \& Ulloa, R. (2006). Creencias de los alumnos y profesores de 1er año de enseñanza media de la intercomuna de Concepción asociadas a la asignatura de matemática. Ponencia presentada en la XIII Jornada de Investigación de Educación Matemática, Concepción, Chile. Recuperado de http://www.sochiem.cl/jornadas2006/ponencias/05.pdf

Chaves, E., Castillo, M., \& Gamboa, R. (2008). Creencias de los estudiantes en los procesos de aprendizaje de las matemáticas. Cuadernos de Investigación y Formación en Educación Matemática, Año 3, (4), 29-44.

Contreras, L. (1998). Marco teórico sobre concepciones acerca de la enseñanza y el aprendizaje de la matemática. Capítulo 2. Tesis doctoral, Universidad de Huelva. España. Recuperado de http://www.uhu. es/luis.contreras/tesistexto/cap2.htm

Contreras, L. (2009). Concepciones, creencias y conocimiento: Referentes de la práctica profesional. Revista Electrónica Iberoamericana de Educación en Ciencias y Tecnología, 1(1), 11-36. Recuperado de http://www.exactas.unca.edu.ar/riecyt/VOL\%201\%20NUM\%201/Doc\%20RIECyT\%201-1.pdf

Cubillo, L., Gamboa, N., Márquez, N., Mora, O., Montero, L., \& Fuentes, V. (2010). Actitud hacia la matemática de las y los estudiantes de tres colegios oficiales urbanos (Memoria del Seminario Licenciatura). Universidad Nacional, Costa Rica.

De Faria, E. (2008). Creencias y matemáticas. Cuadernos de Investigación y Formación en Educación Matemática, Año 3, (4), 9-27.

Domínguez, É., \& Jarero, M. (2010). Creencias de estudiantes de bachillerato sobre la matemática y su relación con la práctica docente. En R. Rodríguez, E. Aparicio, M. Jarero, L. Sosa, B. Ruíz, F. Rodríguez, J. Lezama \& M. Solís (Eds.), Memoria de la XIII Escuela de Invierno en Matemática Educativa (pp. 191-198). Monterrey, México: Red de Centros de Investigación en Matemática Educativa A.C.

Eleftherios, K., \& Theodosios, Z. (2007). Students' beliefs and attitudes concerning mathematics and their effect on mathematical ability. En D. Pitta-Pantazi \& G. Philippou (Eds.), Proceedings of the Fifth Congress of the European Society for Research in Mathematics Education, 258-267. Recuperado de http://ermeweb.free.fr/CERME5b/WG2.pdf

Estrada, A. (2002). Análisis de las actitudes y conocimientos estadísticos elementales en la formación del profesorado (Tesis doctoral). Departament de Didàctica de les Matemàtiques i les Ciències Experimentals. Universitat Autònoma de Barcelona. Recuperado de http://www.tesisenxarxa.net/ TDX-0502103-191818/

Estrada, J., \& Bedoya, J. (2010). Actitud hacia la matemática, un instrumento pedagógico e investigativo. Memorias del Segundo Encuentro Nacional sobre la Enseñanza de las Ciencias Exactas y Naturales. Universidad Católica Popular del Risaralda. Colombia. Recuperado de http://www.ucpr.edu.co/encuentrosdcb/res/ponencias/PO1.\%20J.R.Bedoya\&J.M.Estrada\%20revista.pdf

Fuentes, J., García, S., \& Martínez, C. (2009). ¿En qué medida cambian las ideas de los futuros docentes de secundaria sobre qué y cómo enseñar, después de un proceso de formación? Revista de Educación, 349, 269-294.

Gil, N., Blanco, L., \& Guerrero, E. (2005). El dominio afectivo en el aprendizaje de las matemáticas. Una revisión de sus descriptores básicos. Revista Iberoamericana de Educación Matemática, (2), 15-32. Recuperado de http://www.fisem.org/descargas/2/Union 002 004.pdf 
ISSN Electrónico: 2215-3470

DOI: http://dx.doi.org/10.15359/ru.30-1.4
UNICIENCIA Vol. 30, No. 1, pp. 57-84. Enero-Junio, 2016.

URL: www.revistas.una.ac.cr/uniciencia Email: revistauniciencia@una.cr

Gil, N., Blanco, L., \& Guerrero, E. (2006). El papel de la afectividad en la resolución de problemas matemáticos. Revista de Educación, 340, 551-569.

Gómez, I. (2000). Matemática emocional. Los efectos en el aprendizaje matemático. Madrid: Narcea Ediciones.

Gómez-Chacón, I. (2007). Sistema de creencias sobre las matemáticas en alumnos de secundaria. Revista Complutense de Educación, 18(2), 125-143.

Gómez-Chacón, I., Op’t Eynde, P., \& De Corte, E. (2006). Creencias de los estudiantes de matemáticas. La influencia del contexto de clase. Enseñanza de las Ciencias, 24(3), 309-324.

Goodykoontz, E. (2009). Factors that Affect College Students' Attitudes toward Mathematics. Proceedings for the Twelfth Special Interest Group of the Mathematical Association of America on Research in Undergraduate Mathematics Education. North Carolina, USA. Recuperado de http://sigmaa.maa. org/rume/crume2009/Goodykoontz LONG.pdf

Hassi, M., \& Laursen, S. (2009). Studying Undergraduate Mathematics: Exploring Students' Beliefs, Experiences and Gains. En S.L. Swars, D.W. Stinson \& S. Lemons-Smith (eds.), Proceedings of the 31st Annual Meeting of the North American Chapter of the International Group for the Psychology of Mathematics Education (PME-NA) , 5, 113-121. Atlanta, GA: Georgia State University.

Hekimoglu, S., \& Kittrell, E. (2010). Challenging Students' Beliefs about Mathematics: The Use of Documentary to Alter Perceptions of Efficacy. PRIMUS, 20(4). 299-331. Recuperado de doi http://dx.doi. org/10.1080/10511970802293956

Hernández, G. (2011). Estado del arte de creencias y actitudes hacia las matemáticas. Cuadernos de Educación y Desarrollo, 3(24). Recuperado de http://www.eumed.net/rev/ced/24/ghs.pdf

Hidalgo, S., Maroto, A., \& Palacios, A. (2004). ¿Por qué se rechazan las matemáticas? Análisis evolutivo y multivariante de actitudes relevantes hacia las matemáticas. Revista de Educación, (334), 75-95.

Junor, P., Thomas, C., \& Vidakovic, D. (2009) Preservice Mathematics Teachers' Attitudes and Developing Practices in the Urban Classroom: Are they "Winging" it? Research and Practice in Social Sciences, 5(1), 22-43.

Lazim, M., Abu, M., \& Wan, W. (2004). The statistical evidence in describing the students' beliefs about mathematics. International Journal for Mathematics Teaching and Learning. Recuperado de http:// www.cimt.plymouth.ac.uk/journal/lazimetal.pdf

Lebrija, A., Flores, R., \& Trejos, M. (2010). El papel del maestro, el papel del alumno: Un estudio sobre las creencias e implicaciones en la docencia de los profesores de matemáticas en Panamá. Educación Matemática, 22(1), 31-55. Recuperado de http://www.redalyc.org/articulo.oa?id=40516662003

Llinares, S. (2000). Intentando comprender la práctica del profesor de matemáticas. En J. P. Ponte y L. Serrazina (Eds.), Educaçao matemática em Portugal, Espanha e Itália. Actas da Escoila de Verao-1999, 109-132. Lisboa: Secçao de Educaçao e Matemática. Sociedade Portuguesa de Ciências da Educaçao.

Martínez, O. (2008). Actitudes hacia la matemática. Sapiens, 9(1), 237-256.

Mato, M., \& de la Torre, E. (2010). Evaluación de las actitudes hacia las matemáticas y el rendimiento académico. PNA, 5(1), 25-36.

Meza, G., \& Azofeifa, R. (2011). Actitud hacia la matemática de las y los estudiantes de undécimo año de los colegios del Cantón Central de Cartago. Memorias del VII Congreso Internacional de Enseñanza de la Matemática asistida por Computadora (VII CIEMAC). Cartago, Costa Rica.

Mora, F., \& Barrantes, H. (2008). ¿Qué es matemática? Creencias y concepciones en la enseñanza media costarricense. Cuadernos de Investigación y Formación en Educación Matemática, Año 3, (4), 71-81.

Moreira, T. (2001). Percepciones sobre la formación docente y su posible articulación con la enseñanza de la matemática: Un estudio de casos. Revista Educación, 25(1), 53-66. doi http://dx.doi. org/10.15517/revedu.v25i1.2931 
UNICIENCIA Vol. 30, No. 1, pp. 57-84. Enero-Junio, 2016.

ISSN Electrónico: 2215-3470

URL: www.revistas.una.ac.cr/uniciencia

DOI: http://dx.doi.org/10.15359/ru.30-1.4

Email: revistauniciencia@una.cr

Núñez, J., González-Pienda, J., Álvarez, L., González, P., González-Pumariega, S., Roces, C., Castejón, L., Solano, P., Bernardo, A., García, D., da Silva, E., Rosário, P., \& do Socorro, L. (2005). Las actitudes hacia las matemáticas: Perspectiva evolutiva. En Actas do VIII Congreso Galaico-Portugués de Psicopedagoxía (pp. 2389-2396). Braga: Universidade do Minho; Universidade da Corunha. Recuperado de http://www.guia-psiedu.com/publicacoes/documentos/2005 las actitudes hacia matematicas perspectiva evolutiva.pdf

Pérez, L. (2008). Actitudes y rendimiento académico en matemáticas de los estudiantes que ingresan al primer semestre en la Universidad Sergio Arboleda (Tesis de Maestría). Universidad Sergio Arboleda. Recuperado de http://ima.usergioarboleda.edu.co/pelusa/documentos/pdf/Tesis Eduardo\%20Perez.pdf

Plata, A., \& Trillo, F. (2001). ¿Qué modelos de enseñanza-aprendizaje adoptan los profesores de secundaria de matemáticas? $\mathrm{O}$, ¿cómo los profesores han seguido haciendo lo de siempre pese a la reforma? Enseñanza \& Teaching: Revista interuniversitaria de didáctica, 19, 307-324.

Sánchez, D. (2008). Las creencias en la matemática. Memoria del VI Coloquio de Experiencias Educativas en el contexto universitario, 1-12. Universidad de la Habana. La Habana, Cuba: Editorial Universitaria.

Serres, Y. (2010). El pensamiento del docente, sus prácticas y elementos para su formación profesional. En P. Lestón (Ed.), Acta Latinoamericana de Matemática Educativa, 23 (pp. 1055-1057). México, D.F.: Colegio Mexicano de Matemática Educativa A. C. y Comité Latinoamericano de Matemática Educativa A. C.

Stramel, J. (2010). A naturalistic inquiry into the attitudes toward mathematics and mathematics selfefficacy beliefs of middle school students (Tesis de Maestría). Recuperado de http://search.proquest. com/docview/753921856? accountid $=37045$

Suthar, V., \& Tarmizi, R. (2010). Effects of Students' Beliefs on Mathematics and Achievement of University Students: Regression Analysis Approach. Journal of Social Sciences, 6(2), 146-152. Recuperado de doi http://dx.doi.org/10.3844/jssp.2006.146.152

Tessema, T. (2010). Classroom Instruction and Students' Attitudes Towards Mathematics (Tesis doctoral). Recuperado de http://search.proquest.com/docview/503283774? accountid=37045

Vieytes, S. (2009). Factores que afectan las actitudes hacia las matemáticas en los estudiantes de primer año del curso MATE 3001 de la Universidad de Puerto Rico en Utuado (Tesis doctoral). Universidad de Puerto Rico, Puerto Rico.

Yara, P. (2009). Students Attitude Towards Mathematics and Academic Achievement in Some Selected Secondary Schools in Southwestern Nigeria. European Journal of Scientific Research, 36(3), 336-341. Recuperado de http://www.eurojournals.com/ejsr_36 3 3 02.pdf

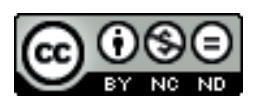

¿Es necesario profundizar en la relación entre el docente de Matemáticas y la formación de las actitudes y creencias hacia la disciplina? (Ronny Gamboa-Araya) por Revista Uniciencia se encuentra bajo una Licencia CreativeCommons Atribución-

NoComercial-SinDerivadas 3.0 Unported. 